\title{
Effect of nanoparticles and polymer nanoparticles implementation on chemical flooding, wettability and interfacial tension for the enhanced oil recovery processes
}

\author{
A. M. El Shafey \\ Chemistry Department, Faculty of Science and Arts, King Khaled University, Sarat Ebida, Saudi Arabia.
}

Accepted 26 September, 2017

\begin{abstract}
The nanotechnology has been widely used in several other industries, and the interest in oil industry is increasing. Nanotechnology has the potential to profoundly change enhanced oil recovery (EOR) and improve the mechanism of recovery, and it is chosen as an alternative method to unlock the remaining oil resources and applied as a new enhanced oil recovery method in the last decade. EOR processes aims to recover trapped oil left in reservoirs after primary and secondary recovery method. Chemical flooding is of increasing interest and importance due to high oil prices and the need to increase oil production. Nanochemical flooding is an immature method from an application point of view. With the decline in oil discoveries during the last decades it is believed that EOR technologies will play a key role to meet the energy demand in years to come. New materials and additives are needed to make EOR economical in challenging reservoirs or harsh environments. Nanoparticles have been widely studied for EOR, but nanoparticles with polymer chain grafted to the surface - known as polymer- coated nanoparticles (PNPs) are an emerging class of materials that may be superior to nanoparticles for EOR due to improved solubility and stability, greater stabilization of foams and emulsions, and more facile transport through porous media. This paper therefore focuses on the reviews of the application of nanotechnology in chemical flooding process in oil recovery and reviews the applications of nanomaterials for improving oil recovery that have been proposed to explain oil displacement by polymer flooding within oil reservoirs, and also this paper highlights a related class of materials comprised of surfactant and nanoparticle blends and studies of PNPs for improving mobility control, altering surface wettability, and for investigating their transport through porous media in EOR applications.
\end{abstract}

Keywords: Nanotechnology, polymer nanoparticles, chemical flooding, reservoir, surfaces and interfaces, wettability, interfacial tension, enhanced oil recovery.

*Corresponding author. E-mail: sommy_28@yahoo.com.

\section{INTRODUCTION}

The October 1973 Arab Oil embargo was not the first warning of impending energy storages - nor was it the first embargo, farsighted individuals had previously called attention to the inevitability of an "energy crunch". The October 1973 embargo did, however, bring the problem "front and centre".

Since the countries, administration, industries and consumers have increasingly realized that the new sources of energy, new attitudes and discipline must be developed and adopted. Clearly, a comprehensive energy program is complex- a unified and complete program must encompass the consideration of all options. The potential of each needs to be explored. Most of the oil fields around the world have reached or will reach soon the phase where the production rate is nearing the decline period. Nowadays, energy 
consumption worldwide is excepted to increase by $50 \%$ relative to current levels by the end of 2030 (Ghauri, 1976). This growth is unlikely to be met by renewable resources, and thus there is a strong and growing demand for oil as a predominant energy resource. Hence, the current main challenge is how to delay the abandonment by extracting more oil economically. Primary and secondary oil recovery methods typically produce only 15 to $30 \%$ of the original in place, depending on the compressibility of fluids and initial pressure of the reservoir (Goolsby, 1965). This leaves large amount of trapped oil in reservoirs, which in some cases is amenable to tertiary or enhanced oil recovery (EOR) processes.

One such option is to produce more oil- to enhance the recovery from domestic oil fields when considered by itself, enhanced oil recovery (EOR) is one of the "building blocks" and an overall energy structure. Increasing production from existing fields may well be a good source of future domestic energy supply. The term "enhanced oil recovery" refers, in the broadest sense, to any method used to recover more oil from a petroleum reservoir than would be obtained by primary recovery.

\section{CHEMICAL WATER FLOODING}

Oil production has three different stages; primary (production by natural reservoir energy), secondary (on the supply of external energy into the reservoir in the form of injecting fluid to increase reservoir pressure) and tertiary production (enhanced oil recovery methods increase the mobility of the oil in order to increase production).

In primary recovery, naturally occurring forces, expansion or influx of water from aquifers, are utilized to produce oil. Chemical EOR processes a variety mechanisms including a reduction in the oil-water interfacial tension (IFT) (Hirasaki et al., 2011; Shah, 1977; Rosen et al., 2005), surface wettability alteration (Downs and Hoover, 1989; Buckley et al., 1998; Buckley and Liu, 1998; Hirasaki and Zhang, 2004; Morrow, 1990), the use of high viscosity agents for mobility control (Stahl and Schulz, 1988; Taber, 1981; Pope, 1980; Taylor and Nasr-El-Din, 1998), application of thermal methods whereby the viscosity of oil is increased by increasing the temperature inside the reservoir (Schmidt and Chevron, 1988; Boberg, 1988; Stahl et al., 1987), and the use of microbes for recovery of depleted reservoirs ( $\mathrm{Li}$ et al., 2002; Donaldson et al., 1989; Lazar et al., 2007; Brown, 2010). EOR processes can include one or more of these mechanisms, and to be successful the approach must be economical, scalable, and reliable. The petroleum industry has conducted extensive research on enhanced oil recovery since $1930 \mathrm{~s}$. As a result, several potential processes have been developed and field tested. Some of these processes are designed to recover the oil left in reservoir after water flooding or following other conventional secondary recovery processes. The EOR processes-usually the third type of recovery method employed in the reservoir- has been called "tertiary" recovery methods. Because some of the enhanced recovery by processes may be used as an alternative to water-flooding or other conventional secondary recovery processes, the term "enhanced oil recovery" is considered to have a broader meaning than "tertiary" oil recovery. Conventional secondary recovery methods, such as water floods, are considered to be "enhanced recovery" methods under the broader definition. Water flooding of reservoirs, in which water is injected to supplement original reservoirs forces and drive more oil to producing wells. For this study, "enhanced oil recovery", or "EOR", is considered in a more narrow sense, and it is defined as the additional recovery of oil from petroleum reservoirs over that which can be economically recovered by conventional primary and secondary methods. Water flooding is the most widely used fluid injection process in the world today. It has been recognized (Talash and Strange, 1982) since 1880 that injecting water into an oil-bearing formation has the potential to improve oil recovery. However, water flooding did not experience injection projects were initiated (Barnes and Tinker, 1985; Holbert and Zeito, 1960), and it was not until the early 1950's that the current boom in the water flooding began. Water flooding is responsible for a significant fraction of the oil currently produced. Many complex and sophisticated enhanced recovery processes have been developed through the years in an effort to recover the enormous oil reserves left behind by inefficient primary recovery mechanisms. Many of these processes have the potential to recover more oil than water flooding in a particular reservoir. However, no process has been discovered which enjoys the widespread applicability of water flooding.

The primary reasons why water flooding is the most successful and most widely used oil recovery process (Criag, 1971, 1973):

i. general availability of water.

ii. low cost relative to other injection fluids.

iii. ease of injecting water into a formation.

iv. high efficiency with which water displaces oil.

\section{Factors controlling water flood recovery}

Oil recovery to water flooding can be determined at any time in the life of water flood project if the following four factors are known.

\section{Oil-in-place at the start of water flooding}

The oil-in-place at the time of initial water injection is a 
function of the floodable pore volume and the oil saturation. Floodable pore volume is highly dependent on the selection and application of net pay discriminators such as permeability (and porosity) cutoffs. A successful flood requires that sufficient oil be present to form an oil bank as water mores through the formation.

An accurate prediction of water flood performance or the interpretation of historical water flood behavior can only be made if a reliable estimate of oil-in-place at the start of water flooding is available.

\section{A real sweep efficiency}

This is the fraction of the reservoir area that the water will contact. It depends primarily upon the relative flow properties of oil and water the injection-production well pattern use to flood the reservoir, pressure distribution between the injection and production wells, and directional permeability.

\section{Vertical sweep efficiency}

Vertical sweep refers to the fraction of a formation in the vertical plane which water will contact. This will depend primarily upon the degree of vertical stratification existing in the reservoir.

\section{Displacement sweep efficiency}

This represents fraction of oil which water will displace in the portion of the reservoir invaded by water.

Water flood recovery can be computed at any time in the life of a water flood project from the following general equation:

$N_{p}=N * E_{A^{*}} E_{v} * E_{D}$

$\mathrm{N}=$ The oil in place in the floodable pore volume of the start of water injection, STB.

$E_{A}=$ The fraction of the floodable pore volume area swept by the injected water.

$E_{v}=$ The fraction of the floodable pore in the vertical plane swept by the injected water.

$E_{D}=$ is equal to the fraction of oil saturation at the start of water injection which is displaced by water in that portion of reservoir invaded by water.

Water flood recovery is dependent on a number of variables. The variables which usually have the greatest impact on water behavior are listed as follows:

- Oil saturation at the start of water flooding, $S_{0}$.

- Residual oil saturation to water flooding, $S_{\text {or }}\left(S_{o r w}\right)$.

- Connate water saturation, $\mathrm{S}_{\mathrm{wc}}$.
- Free gas saturation at the start of water injection, $S_{y}$.

- Water floodable pore volume, $V_{P}$, BBLS (This takes into account the permeability or porosity net pay discriminator).

- Oil and water viscosity, $\mu_{0}$ and $\mu_{\mathrm{w}}$.

- Effective permeability to oil measured at the immobile connate water saturation, $\left(\mathrm{K}_{0}\right) \mathrm{S}_{\text {wir. }}$.

- Relative permeability to water and oil, $\mathrm{k}_{\mathrm{rw}}$ and $\mathrm{k}_{\mathrm{ro}}$.

- Reservoir stratification, (Dykstra-Parsons coefficient, V).

- Water flood Pattern (Symmetrical or irregular).

- Pressure distribution between injector and producer.

- Injection rate, BWPD.

- Oil formation volume factor, $\mathrm{B}_{0}$.

- Economics.

\section{Water flooding versus maintenance}

Maximum combined primary and secondary oil recovery occurs when water flooding is initiated at or near the initial bubble point pressure.

When water injection commences at a time in the life of a reservoir when the reservoir pressure is at a high level, the injection is frequently referred to as a pressure maintenance project.

On the other hand, if water injection commences at a time when reservoir pressure has declined to a low level due to primary depletion, the injection process is usually referred to as a water flood.

In both instances, the injected water displaces oil and is a dynamic displacement process. Nevertheless, there are important differences in the displacement process which occurs in depleted low pressure reservoirs. Wettability concepts and the location of oil and connate water in the layer pores can be illustrated with a simple diagram. Consider the "large" pore in Figure 1. However, all rocks exhibit a range of pore sizes which causes a variation in capillary pressure with fluid saturation. In general, the slope of the capillary pressure curve will increase with increasing pore size heterogeneity. This is illustrated by curves 2, 3, and 4 on Figure 2 which represent a homogeneous, moderately heterogeneous, and very heterogeneous reservoir, respectively.

\section{NANOTECHNOLOGY IN PETROLEUM INDUSTRY}

Since, the past decade, rapid development in nanotechnology has produced several aspects for the scientists and technologies to look into (Mishra et al., 2014). Nanoparticles are particles with the dimensions in the order of 1 to $100 \mathrm{~nm}$. They possess unique properties due to their small sizes and greater surface area per unit volume (Singh and Ahmed, 2010). Various nanofluids can be designed by the addition of nanoparticles to different base fluids. The stability or dispersion of nanoparticles in solutions relies on the functionality 


\section{PLANE VIEW, CROSS.SECTION VIEW, AND FLUID DISTRIBUTION IN A HYPOTHETICAL WATER-WET, OIL-WET, AND FRACTIONAL-WET PORE}

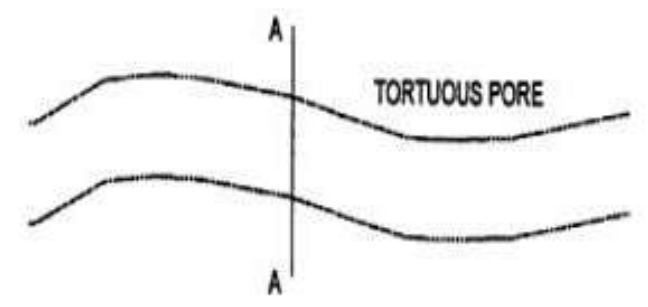

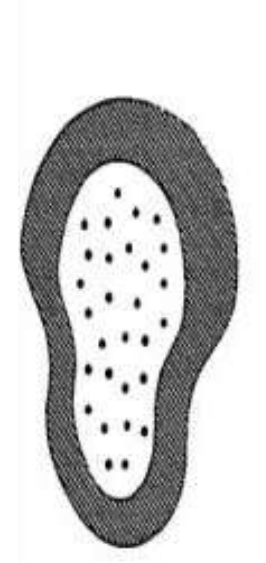

WATER-WET

\section{PORE CROSS-SECTION AT POSITION A-A}

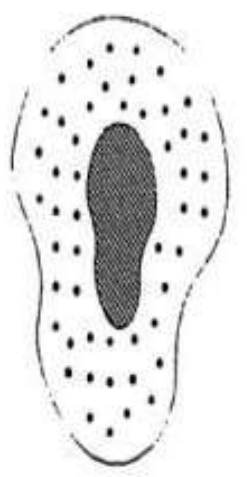

OL.WET

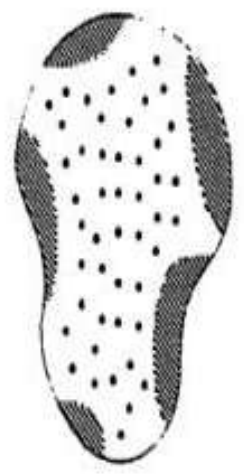

CONANE WATER
$\therefore \because \because{ }^{\circ}$

Oll

Figure 1. Plane view, cross-section view, and fluid distribution in a hypothetical water-wet, oil-wet, and fractional-wet pore.

(or surface activity) of the nanoparticles. To this end, the surfaces of nanoparticles are usually treated or functionalized, thereby putting shields around them. These shields hinder particle-particle interaction, and the possibility of nanoparticle aggregation is reduced. Nanoparticles have been explored for use in remarkable range of applications (Matteo et al., 2012), including polymer composites (Kumar et al., 2013), drug delivery (Soppimath et al., 2001; Kumari et al., 2010; Qian et al., 2006; Zhang and Misra, 2007; Liong et al., 2008; Torchilin and Trubetskoy, 1995), sollar cells (Zhang et al., 2006; Wang et al., 2003; Saunders and Turner, 2008; Briseno et al., 2010), lipase immobilization (Yong et al., 2008), metal ion removal (Takafuji et al., 2004), imaging (Liong et al., 2008; Lu et al., 2007; Li and Ruckenstein, 2004) and EOR (Matteo et al., 2012). Nanotechnology in petroleum industry has gained enormous interest in the recent years, which is reflected in the amount literature available (Engese, 2012).

\section{NPs for EOR processes}

Nanoparticles for EOR purposes seem gradually to become the cutting-edge technology (Engese, 2012). They can be interfacially active and used to modify surface properties. Nanoparticles have been shown to stabilize foams and emulsions or change the wettability of rock, but their successful implementation for EOR processes require considerations beyond interfacial properties. They must be able to migrate through enormous media and be desirable in water/brine, inexpensive, and inject able to a reservoir. Kanj et al. (2009) identified the usable size of nanoparticles in reservoir rocks through nano-fluid core flooding experiments. Adding nanoparticles to fluids may significantly benefit enhanced oil recovery and improve well drilling, such as changing the properties of the fluid, wettability alteration of rocks, advanced drag reduction strengthening and consolidation reducing the interfacial tension and increasing the mobility of the capillarytrapped oil (Cheraghian et al., 2014). In the past decade, most investigations have shown that nanoparticles (NPs) our promise for future enhanced oil recovery (EOR) processes where silica-based NPs have been most commonly used (Ju et al., 2006; Miranda et al., 2012; Roustaei et al., 2013; Cheraghian and Tardasti, 2012; Hendraningrat et al., 2013). Although the oil displacement 


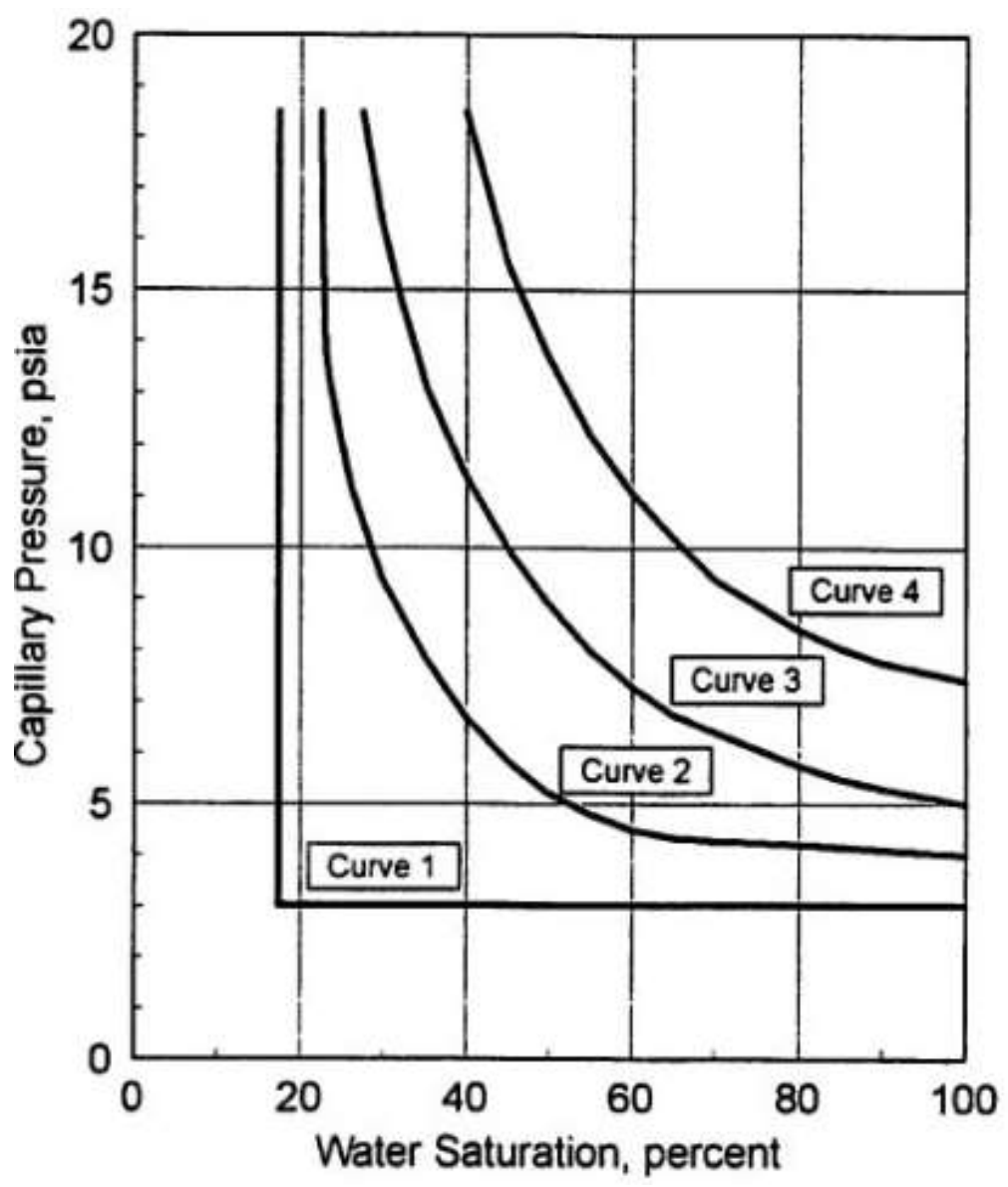

Figure 2. Effect of reservoir heterogeneity on capillary pressure curves.

mechanism via NPs is not yet clearly understood (Wasan and Nikolov, 2003; Wasan et al., 2011; Chengara et al., 2004), the nanotechnology is now chosen as an alternative method to unlock the remaining oil resources and applied as a new enhanced oil recovery (EOR) method in last decade (Hendraningrat et al., 2013; Miranda et al., 2012; Roustaei et al., 2013; Ju et al., 2006; Ogolo et al., 2012; Hendraningrat and Torsaeter, 2014; Torsaeter and Hendraningrat, 2013). Polymeric micro-spheres and nanospheres have been applied as water mobility control both as a pilot and full-yield, and showed fantastic results in reducing water cut, increasing sweep efficiency and improving oil recovery (Yuan et al., 2010; Li et al., 2012; Tian et al., 2012). Also, Tian et al. (2012) reported that polymeric microspheres and nanospheres can swell when meet with water and then reduce water permeability due to its ability of reducing the capillary force and change water upon path. Consequently water goes into bypassed area and enhances displacement efficiency. They also reported that polymeric microspheres and nanospheres have some advantages such as no degradation at high temperature and salinity. Table 1 shows nanoparticles utilized for enhanced oil recovery in IFT process.

\section{PNPs for EOR processes}

One approach to improve the dispersibility of nanoparticles and tailor their properties for a particular application is to covalently attach polymers to the nanoparticle surface, resulting an polymer- coated nanoparticles (PNPs). PNPs have received significant interest as additives and interfacially active materials, and more recently they have been investigated for EOR applications. PNPs are versatile materials that can be tailored for a particular application, such as EOR. Some papers also address experiments where combinations of nanoparticles and surfactant solutions are tested. Li et al. studied synergistic blends of $\mathrm{SiO}_{2}$ nanoparticles and surfactants for EOR in high temperature reservoirs. While less work has been carried out with PNPs for EOR, recent work suggests they may be superior to unmodified nanoparticles for EOR. The aim of this particle to review work related to PNPs for EOR, including their use as mobility control agents and for wettability alteration (Figures 3 and 4). The author focused only on the studies related to the use of PNPs for EOR. Other oilfield applications, such as hydrocarbon detection and estimation (Hwang et al., 2012), tracing, imaging 
Table 1. List of studies carried out on EOR via nanofluids.

\begin{tabular}{|c|c|c|c|c|}
\hline References & NP type & NP conc. & Dispersion medium & Porous media \\
\hline Onyekonwu and Ogolo (2010) & $\begin{array}{l}\text { Hydrophilic, neutralized and } \\
\text { hydrophobic silica }\end{array}$ & $0.2-0.3 w t \%$ & Ethanol and water & Sandstone cores \\
\hline Suleimanov et al. (2011) & Hydrophobic silica & $0.001 w t \%$ & $\begin{array}{l}\text { Sulfanol alkyl aryl } \\
\text { Sodium sulfonate }\end{array}$ & Quartz sand \\
\hline Shahrabadi et al. (2012) & Zirconium oxide & $0.1-0.4 w t \%$ & Ethanol & Sandstone cores \\
\hline Karimi et al. (2012) & Hydrophilic silica & $5-10 w t \%$ & $\begin{array}{l}\text { Mixture of nonionic surfactant (Tween } 80 \\
+ \text { Span } 85+\text { glycerin) and DIW }\end{array}$ & Carbonate cores \\
\hline Hendraningrat et al. (2013) & & $0.01,0.05$ and $0.1 \%$ wt & Brine (NaCl 3 wt\%) & Berea sand stone cores \\
\hline Ziad et al. (2013) & $\begin{array}{l}\text { Zinc oxide and aluminium } \\
\text { oxide }\end{array}$ & $0.05 \%$ wt & $\begin{array}{l}\text { Mixture of sodium dodecyl sulfate and } \\
\text { DIW }\end{array}$ & Glass bead \\
\hline Koustaei et al. (2013) & Hydrophobic silica & $0.1-0.4 \%$ wt & Ethanol & Standstone cores \\
\hline Ehtesabi et al. (2014) & Titanium dioxide & $0.01 \%$ and $1 \%$ wt & Brine (NaCl 0.5 wt\%) & Standstone cores \\
\hline Hendraningrat and Torsaeter (2014) & $\begin{array}{l}\text { Aluminim oxide, } \\
\text { dioxide, and silica }\end{array}$ & $0.05 \%$ wt & Brine (NaCl 3 wt\%) & Standstone cores \\
\hline
\end{tabular}

Source: Zhang et al. (2006).
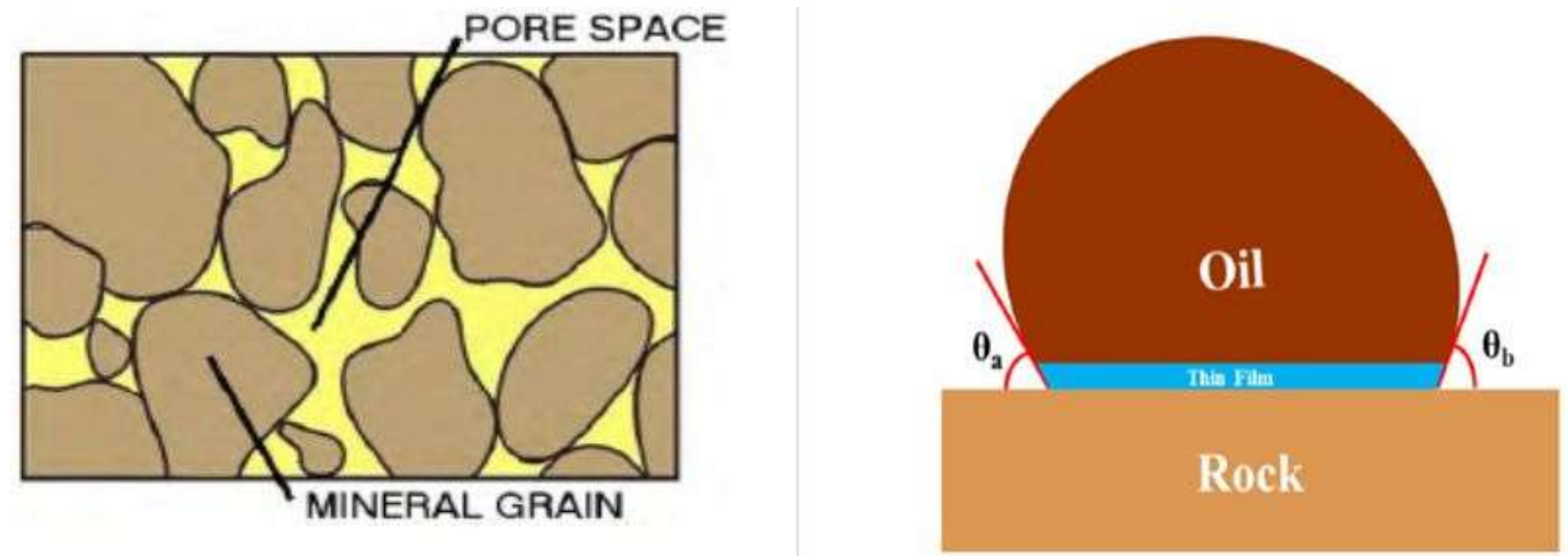

Figure 3. A conceptual model of thin water film formed between oil / brine and brine solid interface. 


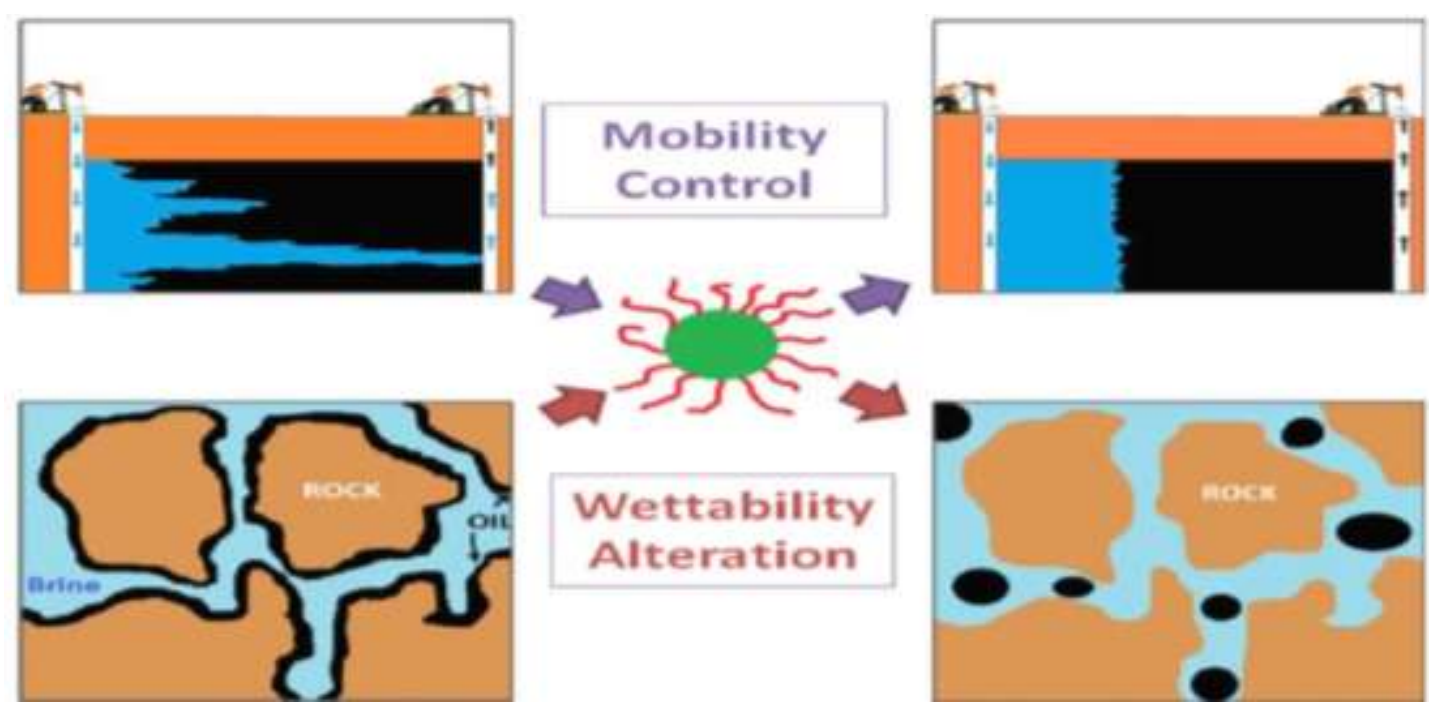

Figure 4. Schematic for the application of PNPs in EOR through mobility control and wettability alteration.

(Xiangling and Ohadi, 2010), etc. are beyond the scope of this study. A significant amount of work has been carried out on polymeric composite based on PNPs (Akcora et al., 2009; Maillard et al., 2012; Kumar et al., 2013; Kim and Green, 2010; Maillard et al., 2011). For additional information, the reader is referred to recent reviews on polymer nanocomposites (Kumar et al., 2013), on simulation responsive PNPs (Cayre et al., 2011), and on the synthesis of PNPs (Quaroni and Chumanov, 1999; Mandal et al., 2002; Rungta et al., 2012). Hamedi shokrlu and Babadagli (2010) investigated effects on nano metals on viscosity reduction of heavy oil and bitumen for thermal oil recovery applications. Based on their obtained results, various parameters such as nanoparticle types, size and concentration could effect on the mechanism of the viscosity reduction of heavy oil/bitumen. In addition to various applications of nanotechnology in petroleum upstreams, enormous researches have been made on the title of implementing of nano-particles on the enhanced oil recovery (EOR) from petroleum reservoirs (Hendraningrat et al., 2012). Hence, in some studies the applications of nanoparticles in oil industry have been reported and classified based on priority. So, researchers have concluded that nanotechnology has the greatest usage in chemical EOR methods (Pourafshary et al., 2009). Therefore, in some studies the role of nanoparticles in EOR operations has been reported (Skauge et al., 2010; Cheraghian et al., 2014; Cheraghian et al., 2014). Subsurface applications of nanotechnology seem to be promising in modifying and monitoring reservoir properties, such as wettability and interfacial tension between rock and fluids. For instance the capability of $\mathrm{SiO}_{2}$ nanoparticles to alter the wettability of reservoir rock and reduce the interfacial tension between crude oil and brine phases has recently been actively investigated to find implementation in enhanced oil recovery (EOR) (Le et al., 2011). The objective of this paper is to investigate the potential of nanoparticles in chemical flooding for oil recovery. This reviewed and assessed some of the recent advances. Specifically, it aims to explain the contributions of application nano in the polymer and surfactant flooding on the wettability process. Figures 3 and 4

\section{Polymer}

Polymer flood is the most widely used chemical EOR method. By adding polymers to water, the water-oil mobility is lowered. Such a change can lead to better sweep efficiency. It is generally believed that polymer flooding cannot reduce the residual oil saturation, but it can help to reach the residual oil saturation in shorter time (Du and Guan, 2004). Polymer flood was proved technically and economically successful in many EOR projects worldwide (Wang and Dong, 2009; Sheng, 2011). In field applications, polymer fluids increased recovery by 12 to $15 \%$ (Wang et al., 2002). The field experience in China showed that polymer fluid was cheaper than water fluid, due to increased oil output and reduced costs in water injection and treatment (Wang et al., 2003). Currently, polymer flooding is considered as one of the most promising technologies in EOR process because of its technical and commercial feasibility. Particularly, the interest on polymer flooding application worldwide has been simulated by the outstanding results reported from the large- scale polymer flooding application in the Daqing oil field in China, with incremental oil production of up to 300,000 barrels per day (Wang et al., 2001).

In practice, two commercial polymers, hydrolyzed polyacrylamides (HPAM) and xanthan gums, are 
commonly used in oil field applications. HPAM is a water soluble polyelectrolyte with negative charges on the polymer chains. Xanthan gums, which are polysaccharides, show excellent viscosifying ability, high tolerance to salinity, and temperature (Guo et al., 1999). However, the current widely used polymers, polyacrylamide (PAM) and partially hydrolyzed polyacrylamide (HPAM), cannot completely the requirements due to the hydrolysis, degradation, and others under high temperature or high salinity (Ye et al., 2013). Furthermore, PAM and HPAM have poor shear resistance (Shiran and Skauge, 2013; Zhong et al., 2007; Ye et al., 2013; Shiran and Skauge, 2013). Polymer molecular chains will be cut out when polymer solution passes through the pump, pipeline perforation, and porous medium at high speed, so the viscosity of polymer solution will be greatly reduced (Chang and Chung, 1991; Xue et al., 2005). Polymer viscosity was seriously affected by salinity. The effect of shearing on polymer viscosity and oil recovery was significant. Thus, high concentration of polymer was utilized to maintain high viscosity (Wu et al., 2014).

\section{Surfactant}

The surfactant-based chemical flooding processes are normally employed to recover the trapped, residual oil after the water flooding. Numerous patents exist on evaluating different factors, which may affect the performance of these processes (Yadali et al., 2009). Surfactant flooding is one of the main mechanisms of reducing interfacial tension between oil and water for the purpose of enhancing oil recovery. Essentially, two different approaches have been developed for using surfactant to enhance oil recovery. In the first approach, a solution containing a low concentration of surfactant is injected. The surfactant is dissolved in either water or oil and in equilibrium with aggregates of the surfactant known as micelles.

Large pore volumes (about 15 to $60 \%$ or more) of the solution are injected into the reservoir to reduce interfacial tension between oil and water, and thereby, increase oil recovery. Oil may be banked with surfactant solution process, but residual oil saturation at a given position in the reservoir will only approach zero after passage of large volumes of surfactant solution. In the second approach, a relatively small pore volume (about 3 to $20 \%$ ) of a higher surfactant concentration solution is injected into the reservoir. The high surfactant concentration allows the amount of the dispersed phase in the micro emulsion to be high as compared with the low value in the dispersed phase of the micelles in the low concentration surfactant solutions. The infected slug is injected with three or more components. The initial components hydrocarbon; surfactant and water are sufficient to form the micellar solutions. A co-surfactant as the fourth component (usually alcohol) can be added. Electrolytes, normally inorganic salts, form a fifth component that may be used in preparing the micellar solutions or micro emulsions. The high concentration surfactant solutions displace both oil and water. As the high concentration slug moves through the reservoir, it is diluted by the formation's fluids and the process reverts to a low-concentration flood. There are numerous mathematical modeling and experimental studies of various aspects of surfactant flooding in the literature (Raterman et al., 1988; Sanz and Pope, 1995; Yang and Wadleigh, 2000; Sanele and Yortsos, 1986; Hornof and Morrow, 1987; Hematpour et al., 2012; Esmaeilzadeh et al., 2014). Le and his colleagues performed experiments blending different types of surfactants with $\mathrm{SiO}_{2}$ nanoparticles. Some of the blends showed great potential for EOR application because of their resistance to adsorption onto the rock surface, and thermo stability at $91^{\circ} \mathrm{C}$ (Le et al., 2011). Suleimanov et al. (2011) carried out experiments which showed how dispersed nanoparticles in an aqueous phase could modify the interfacial properties of a liquid/liquid system, if their surface were modified by the presence of an ionic surfactant. The application of nano-suspension in their study permitted significant increase in the efficiency of oil displacement flow rate.

In homogeneous pore media, oil recovery before water breakthrough was increased by 51 and $17 \%$ for surfactant aqueous solution with nanoparticle addition respectively to water and surfactant aqueous solution (Suleimanov et al., 2011).

\section{Surfactant-polymer}

Surfactant-polymer (SP) flooding processes involve the injection of a surfactant. Polymer slug followed by a polymer buffer and chase water injection. If designed correctly, the surfactant increases the capillary number, which is crucial for the mobilization and recovery of tertiary oil. Polymer increases the sweep efficiency by lowering the mobility ratio. If the reservoir crude oil has sufficient saponifiable components, soap (surfactant) is generated in situ by the reaction of these components with the injected alkali, thus adding more surfactant to the flood (Lake, 1989). Surfactant-polymer interactions in solution are important with regard to the flow behavior in the porous media and the potential to displace the oil (Austad et al., 1994; Taugbel et al., 1995). Furthermore, the surfactant polymer interaction at the solid/liquid interface is extremely important with respect to the loss of chemicals by adsorption onto the minerals of the rock material. The loss of surfactant by adsorption is one of the main factors prohibiting, on economic grounds, the use of surfactants in field applications. In recent years, much attention, both experimental and theoretical, has been focused on surfactant-polymer interactions in 
solution, and several reviews have been published (Breuer and Robb, 1972; Goddard, 1986; Piculell and Lindman, 1992; Lindman et al., 1993). Alkali free SP flooding avoids the drawbacks associated with alkali. Surfactants with concentrations higher than the critical micelle concentration (CMC) can achieve ultra-low IFT. However, such surfactants are expensive. The use of a hydrophilic surfactant mixed with a relatively lipophilic surfactant or a new surfactant was also investigated (Aoudia et al., 2006; Cui et al., 2012; Rosen et al., 2005). However, studies on SP flooding only focused on the screening and evaluation of the polymer and surfactant and their interaction. Reduction in mobility ratio and IFT is influenced by reservoir brine salinity, reservoir temperature, concentration of chemical ingredients an oil components, and others (Ferdous et al., 2012; Gong et al., 2009; Cao et al., 2012; Zhang et al., 2012).

\section{Wettability}

Wettability is defined as the tendency of one fluid to spread on, or adhere to, a solid surface in the presence of other immiscible fluids. This is a major factor controlling the location, flow, and distribution of fluids in a reservoir. Many investigations of wettability and its effects on oil recovery have come to the conclusion that there is a favorable reservoir wettability for operators to recover maximum crude oil from a given subterranean reservoir (Morrow et al., 1984; Morrow, 1990; Anderson, 1987; Rao et al., 1992; Jadhunandan and Morrow, 1995; Zhou et al., 2000; Dwarakanath et al., 2002; Hatiboglu and Babadagli, 2006; Johannesen and Graue, 2007; Yefei et al., 2011). Also, wetting properties are fundamental for the understanding of multiphase flow in all aspects of oil formation and production, and can affect the production characteristics greatly during water flooding. Due to this importance, many reviews of wettability and its effect on oil recovery have been published (Morrow et al., 1986; Cuiec, 1990). The wetting properties of a reservoir are determined by the interactions between rocks and fluids. The type of minerals, pore size distribution and pore surface area are believed to be important, as well as fluid composition and temperature. The wettability can vary from strongly water-wet to strongly oil-wet (Kowalewski et al., 2002).

\section{Effects of nanoparticles on wettability}

In recent years, there has been an increasing interest in application of nanotechnology in petroleum industry. Reservoir engineering, however, have received the most attention for nanotechnology applications. Nanoparticles have been implemented in different enhanced oil recovery processes. Wettability alteration effects and considerable oil recovery were observed for hydrophilic poly-silicon nanoparticles (Ju and Fan, 2009). Yu et al. (2010) introduced iron-oxide cored particles with paramagnetic properties as potential EOR agents of which the behavior can be controlled by imposing an external magnetic field. Onyekonwu and Ogolo (2010) studied capability of three different polysilicon nanoparticles as an agent for wettability alteration and oil recovery purposes. Skauge et al. investigated the oil mobilization properties of nano-sized silica particles and discussed the underlying mechanism of microscopic flowdiversion by colloidal dispersion gels. Surface-coated silica nanoparticles have been used to stabilize both water-in-oil and oil-in-water emulsions. Hendraningrat performed several experimental studies to investigate oil recovery using hydrophilic silica nanoparticle injection. Both secondary and tertiary processes were evaluated. Also Hendraningrat et al. determined the optimum nanoparticle concentration range for enhanced oil recovery purpose in low permeability sandstone reservoirs. Polysilicon nanoparticles (PSNP) have been considered as an EOR agent by Onyekonwu and Ogolo. One important characteristic of polysilicon nanoparticles is its ability to change rock wettability. Onyekonwu and Ogolo discuss three different PSNP which alter the rock wettability in different manners. Their results showed that silane treated NWPN, and hydrophobic and lipophilic polysilicon nanoparticle (HLPN) which is treated by a single layer organic compound, had an improvement of over $50 \%$ after primary and secondary recovery on a water-wet rock (Onyekonwu and Ogolo, 2010). Ju and Fan (2009) address the challenges relating to the application of nano-powder in oil fields to enhance water injection by the effect of changing wettability through adsorption on porous walls of sandstone. Their result revealed that wettability of surface sandstone can be changed from oil-wet to water-wet by adsorption of untreated polysilicon nanoparticle, lipophobic and hydrophilic polysilicon nanoparticle (LHPN). Furthermore, the sandstones effective permeability of water was improved, while a decrease in absolute permeability was observed (Ju and Fan, 2009). In Roustaei and Bagherzadeh (2015) work, the impact of $\mathrm{SiO}_{2}$ nanoparticles on the wettability of a carbonate reservoir rock was experimentally studied. Accordingly, $\mathrm{SiO}_{2}$ nanoparticles are wettability modifiers for carbonate systems, and they can change the wettability of carbonate rocks from strongly oil wet to strongly waterwet condition. Safari (2014) investigated the effect of different concentration of lipophobic-hydrophilic polysilicon nanoparticles (LHPN) on rock surface. He used carbonate rocks in the experiments. The contact angle between oil droplet and rock surface was measured. Finally, results showed that the hydrophilicity and wettability will be increased with increasing nanoparticle concentration and also cores saturated with oil and water was initially mixed-wet, and nanoparticles injection made them water-wet. Water wettability 


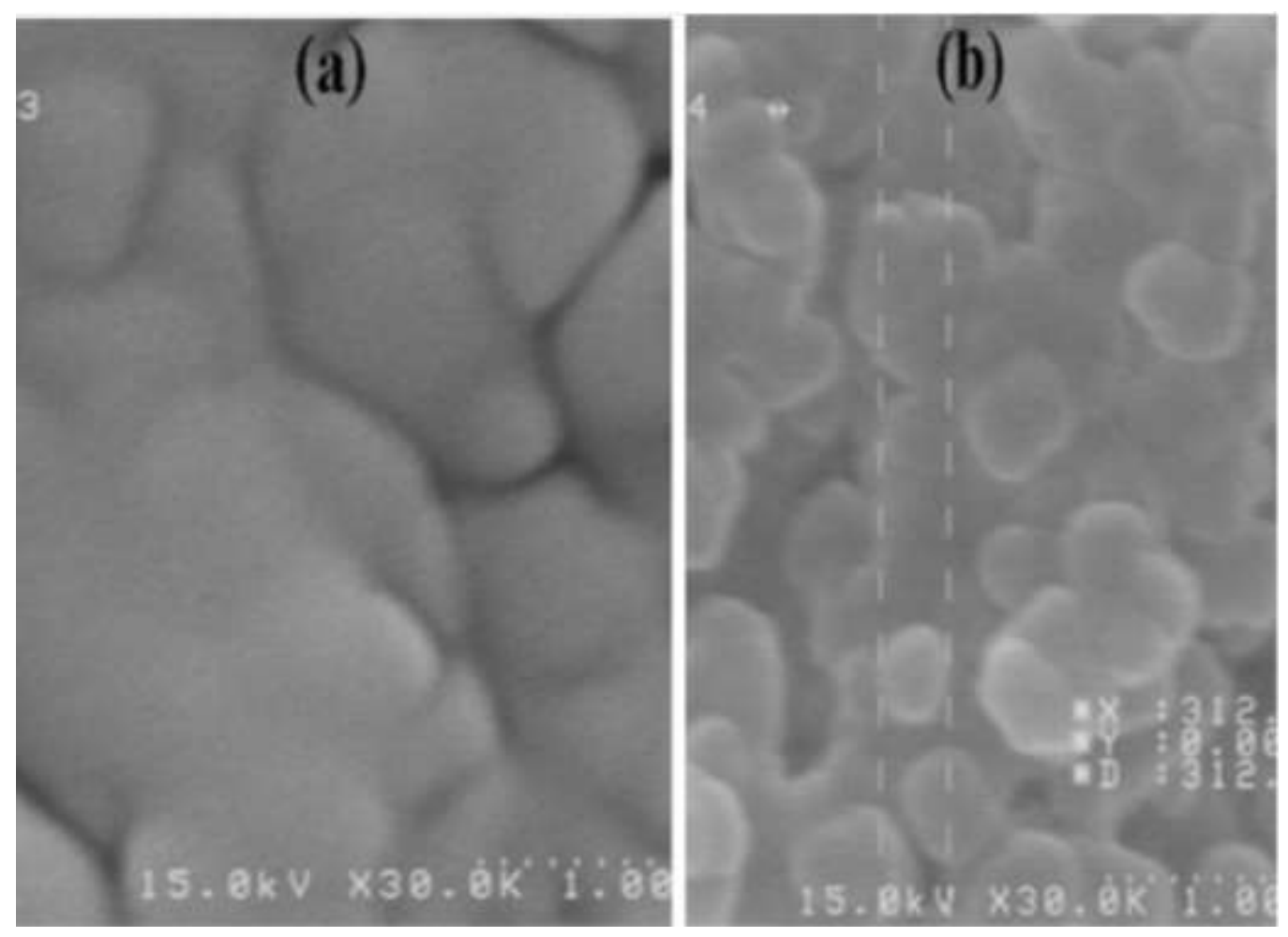

Figure 5. (a) SEM images of carbonate cores nanoparticles suspension. (b) SEM images of carbonate cores after injecting before injecting nanoparticles suspension. Source: Safari (2014).

increases at higher concentrations. The SEM image of the carbonate core after and before injecting with nanoparticles is shown in Figure $5 a$ and $b$. The pictures are taken with 10000 magnifications. Nanoparticles have properties that are potentially useful for certain oil recovery processes, as they are solid and two orders of magnitude smaller than colloidal particles. The nanoparticle stabilized emulsions droplets are small enough to pass typical pores, and flow through the reservoir rock without much retention. Spherical fumed silica particles with a diameter in the range of several to tens of nanometers are the most commonly used. Their wettability is controlled by the coating extent of silanol groups on the surface, and are considered to be hydrophilic if over $90 \%$ of the surface is covered by silanol groups. With these hydrophilic properties, they will consequently form a stable oil-in-water emulsion. Conversely, if the silica particles are coated with only $10 \%$ of silanol groups on the surface, they are hydrophobic, and will form a water-in-oil emulsion (Zhang et al., 2010).

The wettability of a formation can be changed by nanoparticles. The use of nanoparticles to alter rock wettability and its following effect on oil recovery has been published by several authors (Ju and Fan, 2009; Onyekonwu and Ogolo, 2010; Bishan et al., 2005). Ju et al. (2001) reported nanometer polysilicon materials that could change the wettability of porous surfaces.
Polysilicon, of which $\mathrm{SiO}_{2}$ is the main component, is obtained by adding an additive activated by X-ray to form a kind of modified ultra-fine powder with particle size ranging from 10 to $500 \mathrm{~nm}$. A reason for fluid flow behavior during nano-surfactant flooding is the adsorption of $\mathrm{ZrO}_{2}$ nanoparticles onto medium surface and their ability to change the surface wettability from oil-wet to water wet. It is obvious that, among the many features affecting the fluid distribution and oil recovery in porous media, wettability is proven to be a crucial factor (Van Oss and Giese, 1995; Wu and Firoozabadi, 2010). Because of wettability alteration from oil-wet to water-wet by silica nanoparticles, oil recovery after dispersed silica nanoparticles in polyacrylamide solution flooding caused more of the pore space to become saturated with the dispersed silica nanoparticles in polyacrylamide solution resulting in $10 \%$ higher oil recovery than after polymer flooding. In polymer flooding, adding silica nanoparticles to polymer solution can be an acceptable method to enhance oil recovery because besides increasing sweep efficiency by means of polymer, nanoparticles which are present in polymer solution can alter the surface wettability. The fluid behavior in porous media, especially in the wall of pores and throats shows medium wettability of the surface by the dispersed silica nanoparticles in polyacrylamide solution. In parts, the polymer phase has been trapped and oil on the wall of pores and throats has remained and the surface remains oil wet. In some parts, 

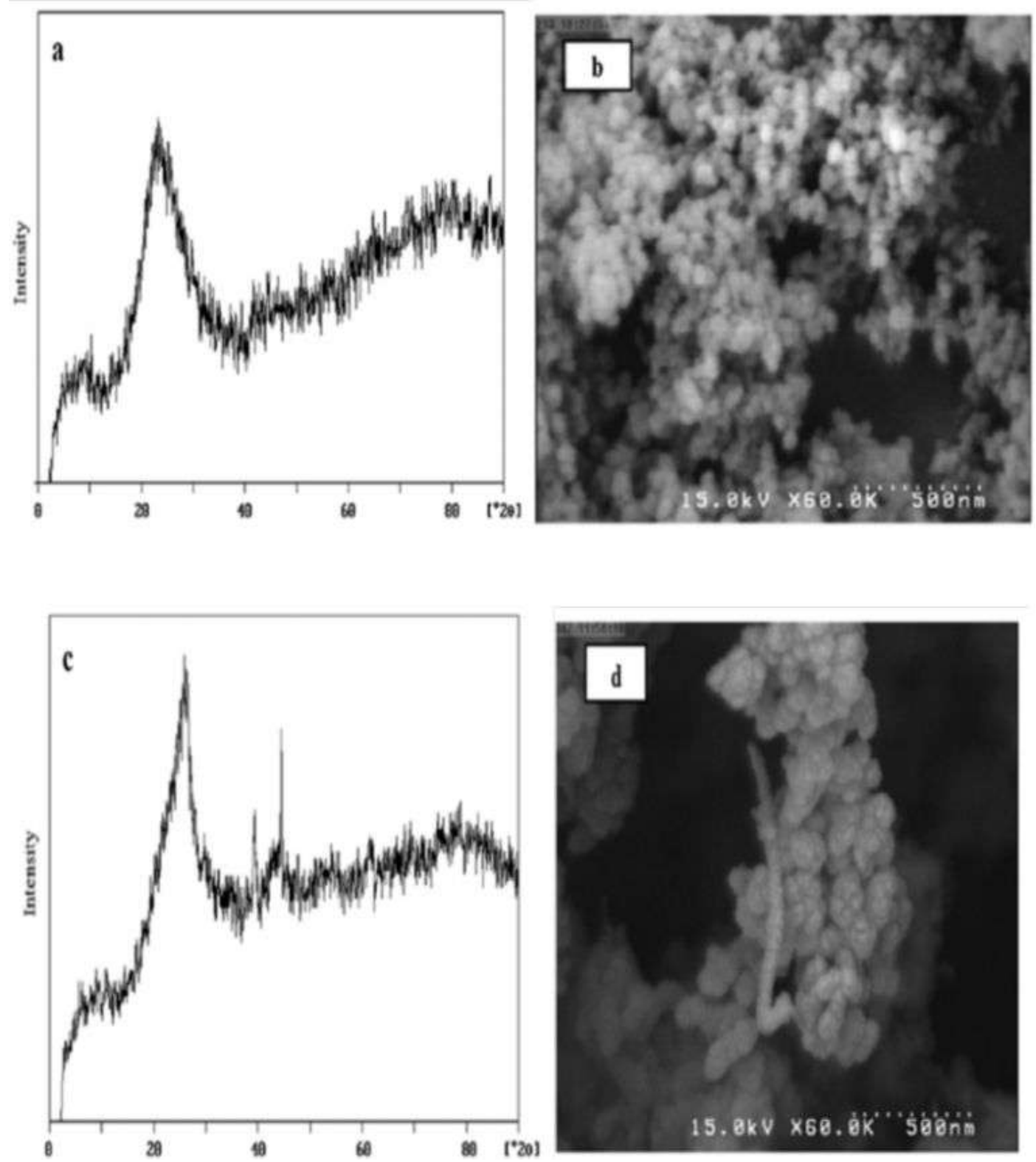

Figure 6. (a and c) XRD Patterns of $\mathrm{SiO}_{2}$ nanoparticles and MWCNT- $\mathrm{SiO}_{2}$ nanohybrid respectively (b and d) FE-SEM images of $\mathrm{SiO}_{2}$ nanoparticles and $\mathrm{MWCNT}-\mathrm{SiO}_{2}$ nanohybrid respectively. Source: Ershadi et al. (2015).

where the polymer phase existed on the wall of pores and throats, no significant oil is existent in pores and throats, and water-wet wettability is dominant (Maghzi et al., 2011).

Multi walled carbon nanotube (MWCNT)-Silica nanohybrid structures are very suitable material for enhanced oil recovery in order to their excellent interfacial activity. In the $\mathrm{O} / \mathrm{W}$ interface, they could change the oil properties to mobilize the oil in the reservoir. The effect of nanofluid includes MWCNT. Silica nanohybrid on the wettability of carbonate and sandstone rocks was investigated by Ershadi et al. (2015). Results were shown that the nanofluid can significantly change the wettability of the rock from oil-wet to water-wet condition.

Figure $6 \mathrm{a}$ and $\mathrm{b}$ show the XRD pattern and FE-SEM image of $\mathrm{SiO}_{2}$ nanoparticles respectively and Figure 6c and $d$ show the XRD pattern and SEM image of MWCNT $\mathrm{SiO}_{2}$ nanohybrid respectively (Ershadi et al., 2015).

Modified silica nanofluid improved oil recovery through major mechanisms of interfacial tension reduction and wettability alteration toward oil-wet condition. Based on contact angle and interfacial experiments, the concentration of $3 \mathrm{~g} / \mathrm{L}$ showed a significant share of 
interfacial tension reduction and high capability in the transformation of wettability toward oil-wet condition. It was considered as the optimum concentration and was employed in core flood experiments for both light and intermediate oil systems. Modified silica nanoparticles are more capable in the reduction of interfacial tension and the alteration of wettability in the case of light oil reservoir (Roustaei et al., 2013).

Experimental unsteady state displacement tests of water/water saturated by dispersed nanoparticles-light crude oil systems were performed on a sandstone core sample and relative permeability curves of both water and oil phases were determined for two successive cycles of both imbibitions and drainage processes.

Based on the results nanoparticles additives have more effect on changing the non-wetting phase relative permeability curves than the wetting-phase (Parvazdavani et al., 2012; Cheraghian and Khalili Nezhad, 2015; Cheraghian, 2015).

The nanofluids change the rock wettability from waterwet to neutral wet state and decrease oil-water interfacial tension (Joonaki and Ghanaatian, 2014). $\quad \mathrm{\gamma}-\mathrm{Al}_{2} \mathrm{O}_{3}$ nanoparticles (Figure 7) can be considered as an effective agent in the changing the wettability of carbonate rock surface from oil-wet to water-wet. Figure 5 shows the construction of nanostructures on the rock surface, which changes the wettability to water-wet conditions (Mohammadi et al., 2014).

\section{PNPs for mobility control}

In the terminology of fluid flow in porous media, mobility of a fluid is defined as the ratio of relative permeability of the corresponding fluid to its viscosity. In EOR, mobility ratio is the mobility of the injected displacing fluid to that of the oil being displaced. Good mobility control is obtained when the viscosity of the injected fluid is higher than the viscosity of the oil in the reservoir and can lead to a piston-like displacement of the oil from the injection well to the production well, as shown schematically in Figure 4. However, poor mobility control due to a lower viscosity of the injected fluid can result in low recoveries due to viscous fingering (Rossen and Gauglitz, 1990; Pope, 1980). For instance, the viscous fingering effect may be observed if $\mathrm{CO}_{2}$ is injected as an oil miscible solvent. Injected $\mathrm{CO}_{2}$ may find the path of less resistance to the production well and bypass most of the oil, leaving a huge portion of the oil in the reservoir behind (Bondor, 1992; Heller, 1994; Lake, 1989; Orr and Taber, 1984). Achieving good mobility control in combination with other mechanisms including low interfacial tension or wettability alteration is therefore essential for successful chemical EOR (Ghauri, 1976; Lake, 1989). A method for achieving high viscosities of the injected phases and good mobility control is through generation of foams and emulsions, which can form in the presence of surfactants or nanoparticles. Foams and emulsions are dispersions of one fluid in a second immiscible fluid, and they typically exhibit high viscosities and shear thinning rheological behaviors (Sani and Mohanty, 2009; Blanco et al., 2013). The high viscosity of the injected phase can lead to improved mobility control. In addition, the shear thinning behavior of the injected foam or emulsion is advantageous for achieving high injection rates into the reservoir. Similar to surfactants, nanoparticles can be used to generate foams and emulsions to increase the viscosity of the injected phase. The stabilization of foams and emulsions using micron sized particles was reported roughly 100 years ago by Ramsden (1903) and later by Pickering (1907). Such emulsions are commonly known as Pickering emulsions. Unlike surfactants, nanoparticles have the advantage that they can irreversibly adsorb to a liquid-liquid or gas-liquid interface, forming very stable foams and emulsions. However, bare nanoparticles may be too hydrophobic or hydrophilic for stabilizing an interface. PNPs can be tailored for a specific interface and application. Below, we discuss the fundamental mechanisms involved in stabilization of foams and emulsions using PNPs and then discuss recent examples of their application for EOR. We begin by discussing surfactant coated nanoparticles, which are closely related to PNPs and have been widely studied for EOR applications.

\section{Foam and emulsion stabilization using surfactant and PNPs}

Surfactant-coated nanoparticles are closely related to PNPs and are prepared by blending surfactants and nanoparticles. Driven primarily by electrostatic interactions, the surfactant can form a monolayer on the nanoparticle surface, resulting in more hydrophobic particles. Figure 8 shows a schematic representation of surfactant adsorption onto a nanoparticle and examples of foams and emulsions stabilized by surfactant-coated nanoparticles.

A number of studies have confirmed surfactant adsorption onto nanoparticles through contact angle measurements, adsorption isotherms of surfactants on nanoparticles, zeta potential measurements and dispersion stability measurements as a function of concentration of surfactant and nanoparticles (Limage et al., 2010; Cui et al., 2010; Binks et al., 2008). Surfactantcoated nanoparticles generate stable foams and emulsions in some cases where precursor nanoparticles or surfactants separately do not (Limage et al., 2010; Worthen et al., 2013; Dong et al., 2010; Siripurapu et al., 2005). The properties of surfactant-coated nanoparticles are dependent on the relative concentrations of surfactant and nanoparticle. If the concentration ratio of surfactant to nanoparticle is low, only a fraction of nanoparticle surface is coated with surfactant. 

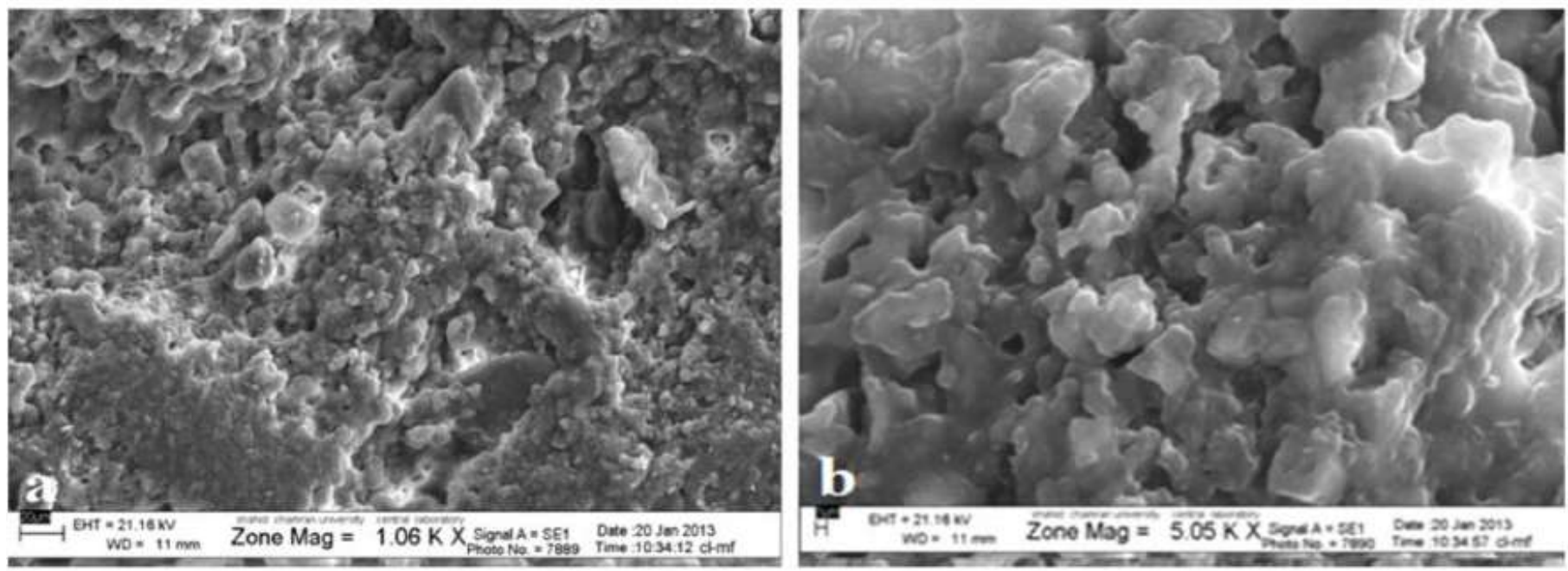

Figure 7. SEM images $\gamma-\mathrm{Al}_{2} \mathrm{O}_{3}$ nanoparticles adsorption on calcite surface with a magnification of (a) 1000 and (b) 5000 . Source: Mohammadi et al. (2014).
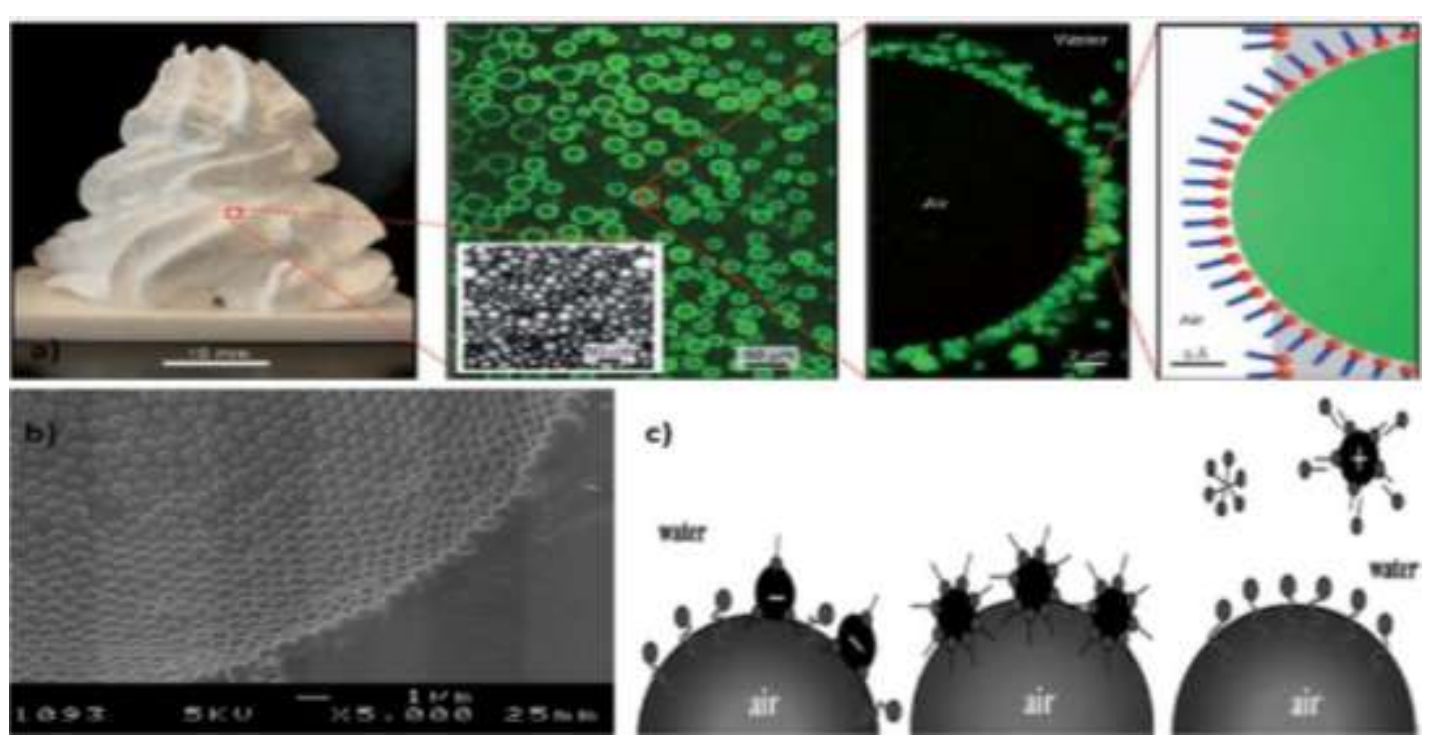

Figure 8. (a) Foam as a viscous fluid is a dispersion of air in water and each air droplet is surrounded by surfactant-coated nanoparticles; (b) Cryo-SEM image of a foam with nanoparticles closed packed; (c) schematic representation of the effect of concentration ratio of nanoparticle and surfactant.

However, at much greater concentration ratios, the surfactant can form a double layer on the nanoparticle surface, resulting in a hydrophilic nanoparticle surface. Stable foams and emulsions are formed at a concentration ratio that results in maximum nanoparticle flocculation (Binks and Rodrigues, 2007). The most flocculated nanoparticle in this case corresponds to a low-charge, optimally hydrophobic nanoparticle, containing a monolayer of surfactant on the surface (Limage et al., 2010; Cui et al., 2010; Binks et al., 2008). Further, single chain surfactants are believed to be a better choice for foam formation when mixed with nanoparticles since double chain surfactants may lead to formation of double layer adsorption on nanoparticle at concentrations lower than that of single chain surfactants (Cui et al., 2010). The rheology of foams and emulsions formed by surfactant coated nanoparticles is also influenced by the surfactant to nanoparticle concentration ratio (Limage et al., 2010). Viscoelastic behavior of the bulk is observed only over a range of concentration ratios. For instance, in a study of silica nanoparticles with a cationic surfactant (cetyl tri-methyl ammonium bromide), Limage et al. (2010) found that if the molar concentration of CTAB to silica nanoparticles is about 
0.03 , viscoelastic behavior is observed. They also try to find a correlation between bulk rheology of nanoparticle and surfactant mixtures and that of the foam. Their rheological measurements are correlated with the structures forming at the interface using cryo-SEM imaging of the generated emulsions and foams. Another role of the surfactant in this process is to lower the interfacial tension and form an initial dispersion of air/water or oil/water in case of foam or emulsion, respectively. Once this dispersion is formed due to shear and a decreased amount of interfacial tension, the stability of foam/emulsion is augmented by adsorption of nanoparticles at the interface (Worthen et al., 2013). Gonzenbach et al. (2006) provide a series of conditions which can result in formation of ultra-stable foams by means of surfactant-coated nanoparticles. Apart from reporting the condition of optimal ratio between concentration of surfactant and nanoparticle, they find that a lower particle size or higher concentration of nanoparticle and surfactant leads to generation of more foam. Also, by comparing long-term stability of the foams treated with different length of surfactants, they find that long term stable foams can be made by using surfactants with a short chain length ( $n=2$ to 8 ) rather than long chain length. Similar to surfactant-coated nanoparticles, PNPs can be used to stabilize foams and emulsions. PNPs can decrease the interfacial tension of oil and water or water and air, which can lead to more stable emulsions. For example, in 2005 Saleh et al. reported the use of silica nanoparticles coated with a polyelectrolyte to stabilize oil-in-water emulsions (Saleh et al., 2005). More recently, Saigal et al. (2010) reported stable oil-in-water emulsions using silica nanoparticles coated with a $\mathrm{pH}$ responsive polymer, and they found that the most stable emulsions were formed at lower polymer chain grafting densities. Related studies on star polymers (Saigal et al., 2013), bottlebrush polymers ( $\mathrm{Li}$ et al., 2014), and paramagnetic particles with adsorbed amphiphilic polymers found stable emulsions and reductions in the oil-water interfacial tension at relatively low (0.1 wt\%) particle contents (Alvarez et al., 2012). Alvarez et al. (2012) evaluated the dynamic reduction in interfacial tension of air and water in the presence of PNPs while changing the grafting density of the polymer brushes and showed that the polymer coating is a key factor in reducing the interfacial tension of air and water using PNPs (Alvarez et al., 2012). PNPs with stimuli-responsive polymer chains have also been reported. PNPs can respond to temperature, $\mathrm{pH}$, and light through a change in surface properties. Stimuli-responsive PNPs can potentially be used to design injectable fluids that respond to environmental changes before and after injection or in the presence of oil. It should be noted that the reduction in interfacial tension by PNPs and star polymers is at most by one order of magnitude (from roughly 25 to $1 \mathrm{mN} / \mathrm{m}$ ) (Saigal et al., 2010, 2013; Li et al., 2014). By comparison, surfactant additives can lead to much greater reductions in oil-water interfacial tension, down to $0.001 \mathrm{mN} / \mathrm{m}^{2}$ and below. Thus, irreversible PNP adsorption to the oil-water interface still plays a predominant role in emulsion stability with added PNPs, but the reduction in oil-water interfacial tension is modest compared with suitably chosen surfactant additives. In addition to surface energy, entropy is important to the interfacial properties of PNPs. Polymers can exhibit conformational changes that influence the thermodynamics of PNP adsorption at the fluid-fluid interface (Du et al., 2010; Isa et al., 2011; Udayana et al., 2010; Garbin et al., 2012). However, there are only a handful of studies on the effect of polymer entropy on nanoparticle adsorption, although this has been studied more carefully in polymer-polymer blends (Sun et al., 2007) and in polymer nanocomposites (Kumar et al., 2013). Surfactant- and PNPs for mobility control prior studies and field tests have relied on the mechanisms explained above to increase the viscosity of the displacing fluid and the recovery of oil (Aminzadehgoharrizi et al., 2012; Nguyen et al., 2012; Yu et al., 2012; Mo et al., 2012, 2013). Foams and/or emulsion formation in oil-rich porous media after injection of surfactant- or PNPs has been validated through CTscans, an increased pressure drop across the core, and effluent analysis (Espinoza et al., 2010; Aminzadehgoharrizi et al., 2012; Zhang et al., 2011). Figure 9 shows the CT-scan of different cross sections of a Boise sandstone core after flooding with brine and $\mathrm{CO}_{2}$, both with and without PEG-coated silica nanoparticles. The difference in these two experiments is only the presence or absence of PNP, and the same core has been scanned at the same injected pore volume of $\mathrm{CO}_{2}$. The CT-scan results show greater sweep efficiency in the presence of PNP (Figure 9b), while with no PNP added, large regions of the core are by-passed due to viscous fingering (Figure 9a). One practical challenge in the application of foam and emulsions from PNPs is the energy needed for foam and emulsion formation (Limage et al., 2010; Cui et al., 2010). There is a threshold shear rate needed for nanoparticles to start generating foams and emulsions (DiCarlo et al., 2011). This threshold injection flow may be much greater than the practical injection rates in reservoirs. In addition, the pregeneration of foams and emulsions outside the reservoir before injection increases the cost and difficulty of injection into the reservoir. It is noteworthy to mention that a type of polymeric nanoparticle with commercial name Bright Water was the first successfully field-tested nanoparticle to increase the sweep efficiency in an actual oil reservoir (Salema field, Campos Basin, Brazil) (Roussennac and Toschi, 2010). Recently, other tests have confirmed the successful application of these nanoparticles in other reservoirs (Towns et al., 2013). Bright Water is a polymeric nanoparticle that hydrolyzes at a specific temperature and expands to many times its original volume. By blocking the pores in the high permeability 

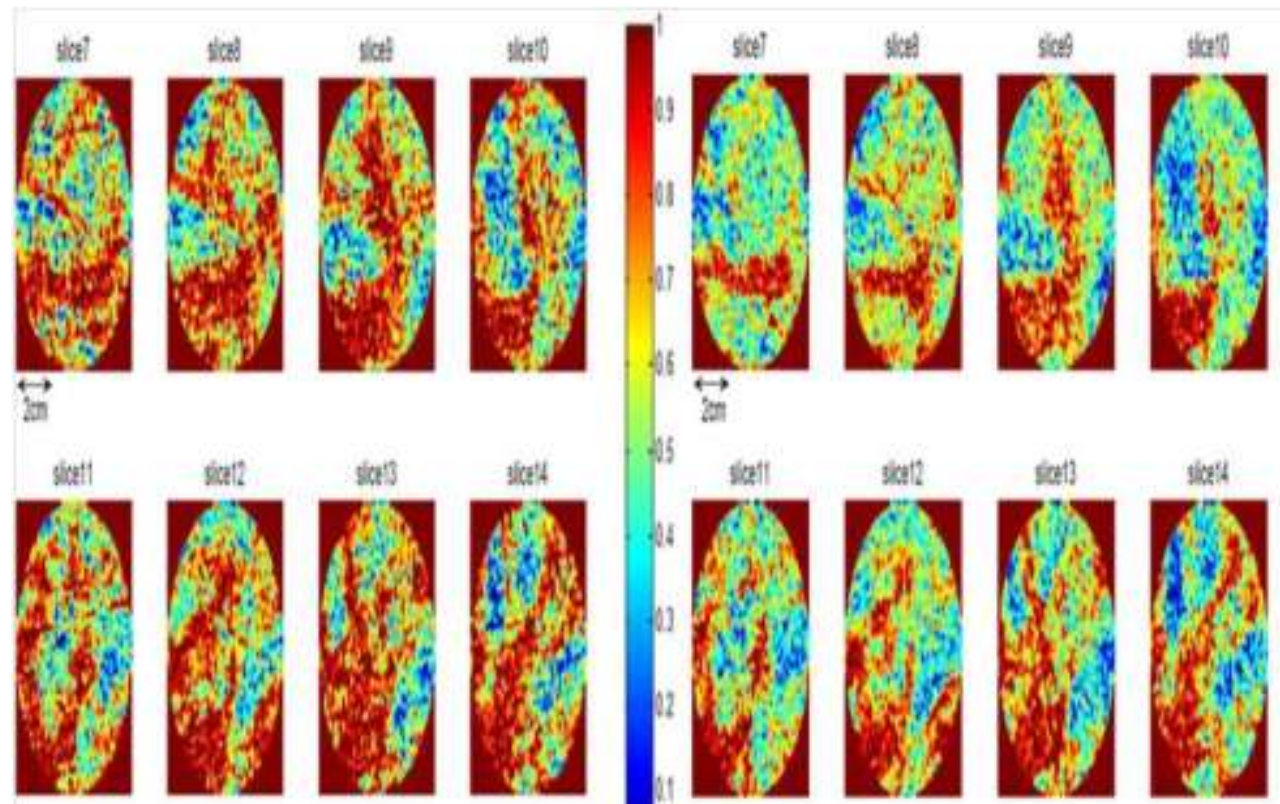

a)
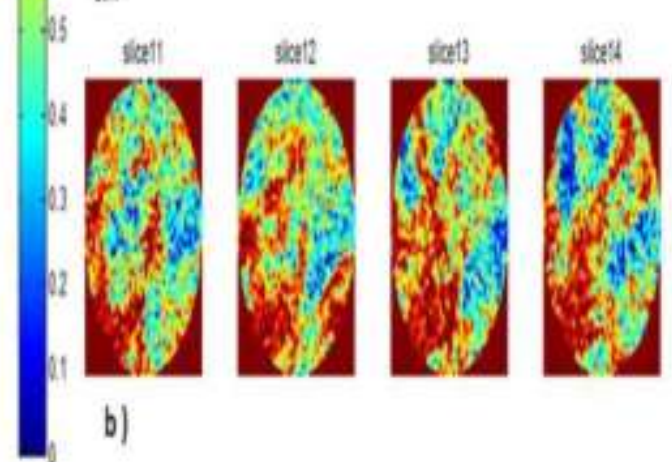

Figure 9. CT-scan of the cross section of a core flooded with $\mathrm{CO}_{2}$ and (a) $2 \% \mathrm{NaBr}$ brine and (b) $2 \% \mathrm{NaBr}$ brine and 5\% PEG-coated silica nanoparticles; pure brine and $\mathrm{CO}_{2}$ are illustrated with red and blue, respectively. The scan is taken after 0.25 pore volume of $\mathrm{CO}_{2}$ injected and each slice is $1 \mathrm{~cm}$ apart longitudinally.

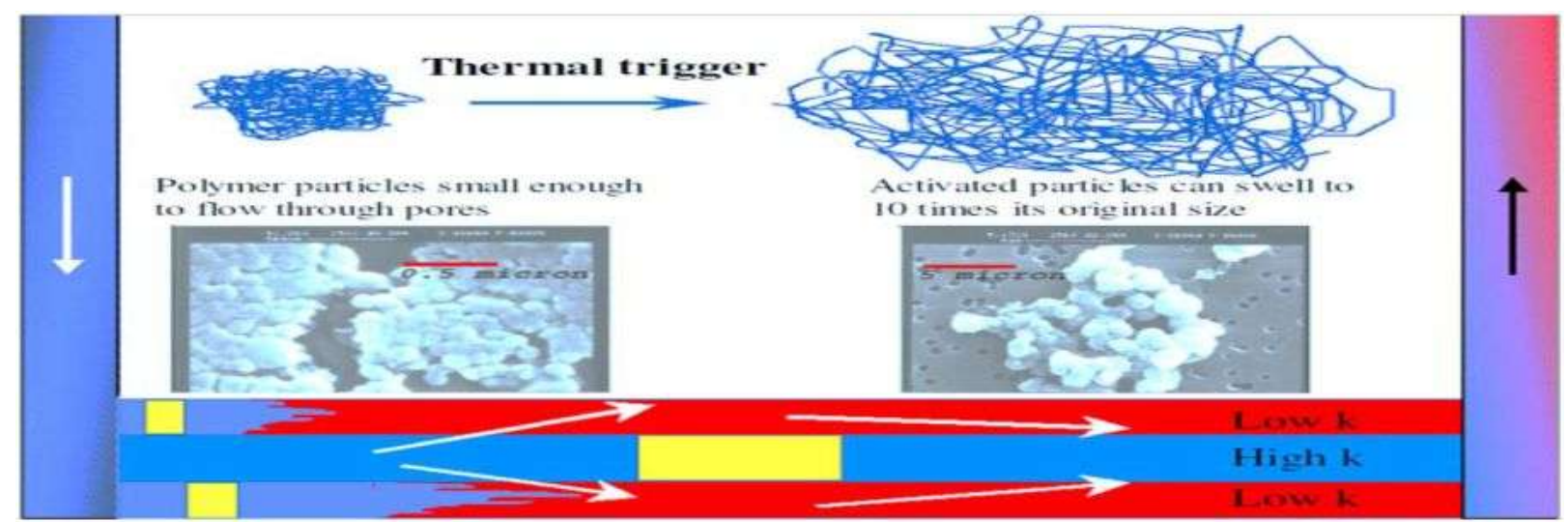

Figure 10. Schematic and SEM image of Bright Water polymeric nanoparticles. The particles expand at elevated temperatures, diverting flow to low permeability regions.

regions of a reservoir, the injected flow will be directed toward low-permeability zones of the reservoir, which may have been previously untouched.

Figure 10 illustrates the basic idea behind the application of these polymeric nanoparticles, which can lead to significant increase in oil recovery. Although Bright Water is not a PNP, its successful implementation provides guidelines for the design of PNPs and demonstrates that PNPs do have potential for use in EOR.

\section{PNPS FOR SURFACE WETABILITY ALTERATION}

Oil can more easily be extracted from water-wet rock than from oil-wet rock (Ju et al., 2006) and one approach to improve oil recovery is through changing the wettability of the reservoir rock from oil-wet towards water-wet. A surface is called water-wet if the water contact angle is $<90^{\circ}$ and oil-wet if the water contact angle is $>90^{\circ}$. Figure 11 demonstrates oil and water spreading on different surfaces. Below, we discuss how nanoparticles and 


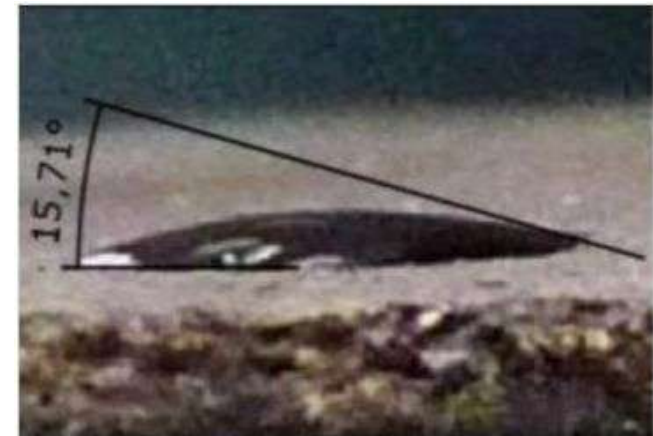

(a)

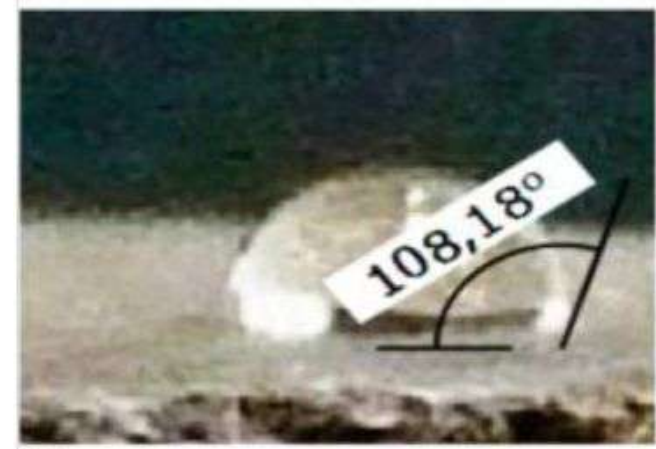

(c)

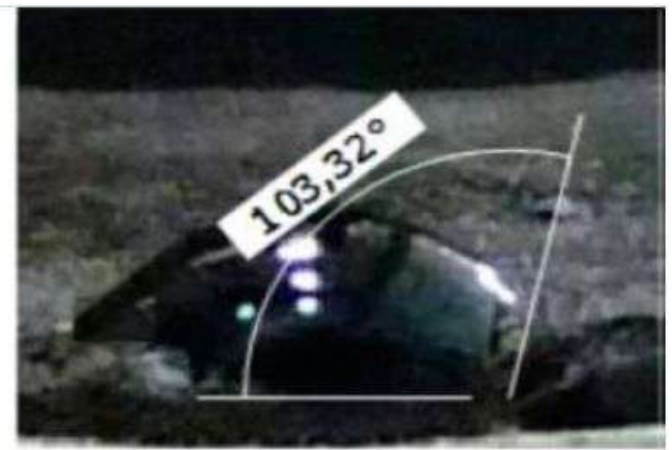

(b)

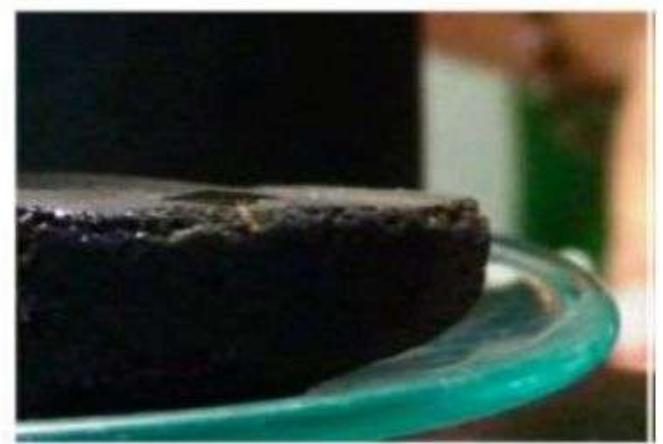

(d)

Figure 11. Contact angle on a rock (a) oil/air/rock before treatment, (b) oil/air/rock after treatment with silica nanoparticles, (c) water/air/rock before treatment, (d) water/air/rock after treatment with silica nanoparticles.

PNPs can alter the wettability of surfaces and then discuss their potential use for wettability alteration in EOR applications.

\section{Mechanisms of surface wettability alteration by PNPs}

Surface and interfacial energies determine whether a surface is water- or oil-wet. A spreading coefficient $S$ of water on a solid in contact with both oil and water can be defined in terms of the interfacial tensions between each phase in equation 2 :

$$
S=\gamma_{0 / s}-\gamma_{w / s}-\gamma_{O / w}
$$

where $\gamma_{0 / s}, \gamma_{w / s}$, and $\gamma_{o / w}$ are the interfacial energies between oil/solid, water/solid, and oil/water. The contact angle formed results from a force balance at these interfaces (Kao et al., 1989). Reducing the oil-water interfacial tension results in an increase in $\mathrm{S}$ and a more water-wet surface. "Rollup" is a well-known mechanism for removal of oily soils from solid surfaces by wettability alteration using surfactants (Salehi et al., 2008). If the initial contact angle is $<90^{\circ}$, it can be decreased to make the surface more water-wet by a reduction in oil-water interfacial tension alone. However, adsorption of surfactant to decrease water/solid interfacial energy is needed to convert an initially oil-wet surface to a waterwet state (Salehi et al., 2008; Dillan et al., 1979). However, in a fluid containing nanoparticles or spherical surfactant micelles, phenomena are observed that may not be fully explained through the previously known mechanisms. Kao et al. were the first to observe that in the case of an oil droplet on a surface immersed in a solution of nanoparticles, there are two contact lines instead of one (Wasan et al., 2011). Also, traditional mechanisms cannot accurately account for the faster spreading of a nanoparticle solution on a surface for higher nanoparticle concentrations and higher viscosities (Giraldo et al., 2013). It is observed that the inner and outer contact lines move with a constant spreading velocity, which is a function of salt concentration, bulk volume fraction of nanoparticles, size, and polydispersity of nanoparticles, as well as interfacial tension between the drop and the spreading phase (Kao et al., 1989; Kondiparty et al., 2012; Chengara et al., 2004; Tata et al., 2000). The underlying mechanism that can account for this unusual interfacial behavior is related to the size of nanoparticles. Adjacent to the wedge-shape inner contact line, the nanoparticles can form ordered structures, as shown in Figure 12 (Chengara et al., 2004; Tata et al., 2000; Wasan and Nikolov, 2003). Chengara et al. (2004) claimed that the ordering is a consequence of increase in entropy of the system. These ordered, solid-like 

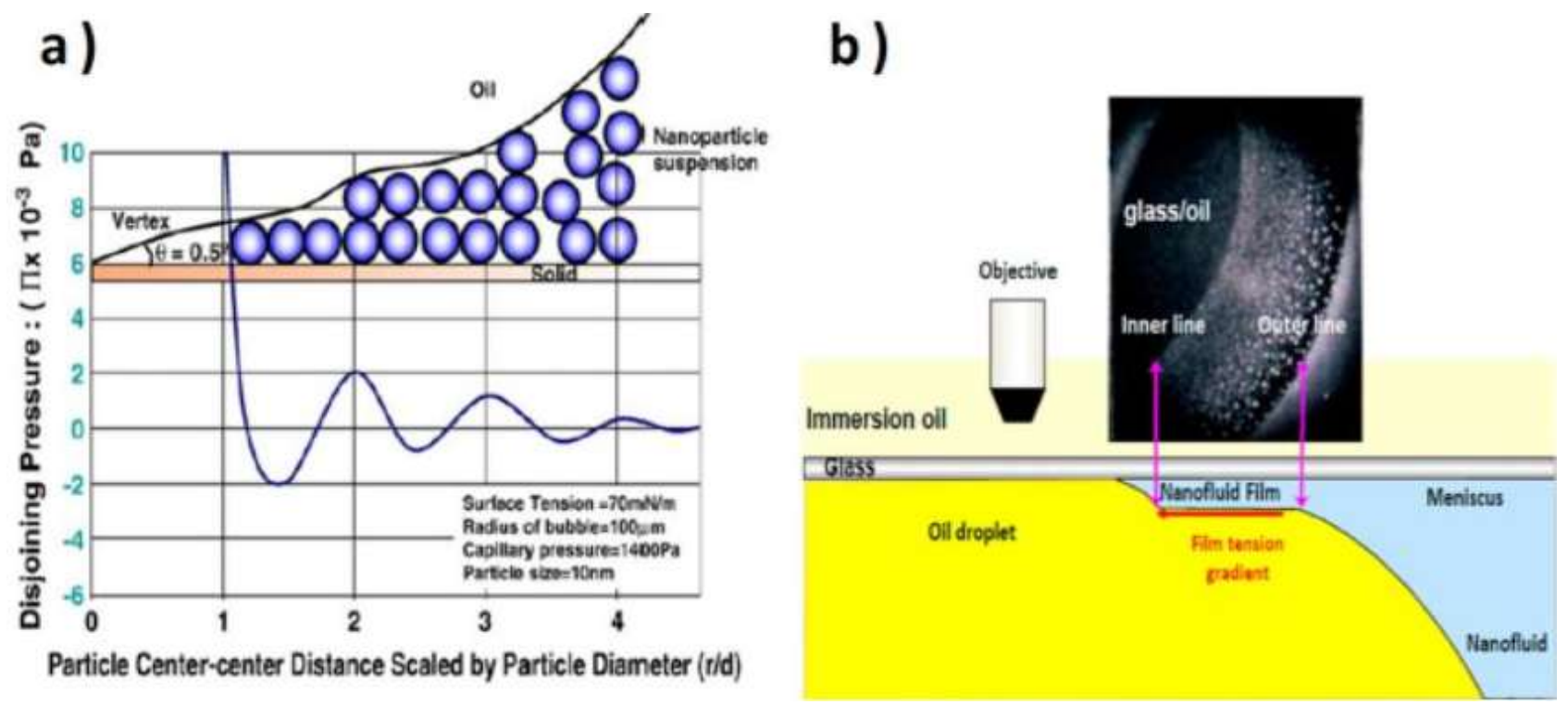

Figure 12. The inner and outer contact line due to ordering of nanoparticles; (a) the oscillatory disjoining pressure profile due to ordering of the nanoparticles near the wedge-like inner contact line; (b) visual and schematic pictures of inner and outer contact lines.

structures near the contact line lead to very high disjoining pressures that caused a wedge-like spreading of the nanoparticle solution, resulting in two contact lines (Figure 12). This structural disjoining pressure is oscillatory (Wasan and Nikolov, 2003), and both period of oscillation and decay factor is dependent to the effective diameter of the nanoparticle (Trokhymchuk et al., 2001). Wasan and Nikolov (2003) showed that the structural disjoining pressure exponentially increases with a decrease in film thickness or number of nanoparticle layers between the solid and oil, as seen in Figure 12 (left). It is the high structural disjoining pressure that enhances the spreading of the phase containing nanoparticles and can lead to wettability alteration of an oil-wet surface to more water-wet states. Matar et al. (2007) showed this theoretically by applying the mass and momentum conservation equations under the lubrication approximation. It is noteworthy that structural disjoining pressure which is discussed in these studies is just one of the components affecting disjoining pressure. Van der Waals, electrostatic, and solvation forces are other components that can affect the disjoining pressure. In particular, electrostatics can be very effective in increasing wettability alteration properties of nanoparticles. If the nanoparticle is coated by a polyelectrolyte, electrostatic repulsive forces can increase the disjoining pressure and may cause significant increase in spreading of the phase with dispersed nanoparticles. In some of the studies that investigate wettability alteration through so called "nanofluids", a mixture of nanoparticle and surfactant is used (Liu et al., 2012; Karimi et al., 2012). However, it is well-known that surfactants of different types are able to change the wettability of the rocks (Standnes and Austad, 2003). Therefore, such studies may not present conclusive evidence on wettability alteration using nanoparticles, especially when control experiments are lacking. In spite of this, there is conclusive evidence that shows nanoparticles can change the contact angle of an at least slightly oil-wet rock to more water wet conditions (Girald

\section{Nanoparticle EOR processes through wettability alteration}

A number of studies have reported the application of nanoparticles in EOR through wettability alteration (Liu et al., 2012; Karimi et al., 2012; Torsaeter et al., 2013; Mcelfresh et al., 2012), yet studies of the effect of PNPs on wettability is in the early stages. Here, we briefly review the current state of research on the effect of nanoparticles on wettability alteration and emphasize how a polymer coating in PNPs can potentially change the contact angle of the nanoparticles, increase electrostatic repulsion, and improve wettability alteration of nanoparticles.

Several studies measured the contact angle of oil-wet surfaces before and after treatment with nanoparticles, and it was found that nanoparticles can decrease the contact angle of various surfaces. Addition of nanoparticles to brine can also lead to spontaneous imbibitions of the nanoparticle dispersion with resulting oil displacement from different rocks (Figure 13) (Torsaeter et al., 2013; Mcelfresh et al., 2012; Ogolo et al., 2012). Relative permeability curves of oil and water also change after contact with nanoparticles; that is, the relative 


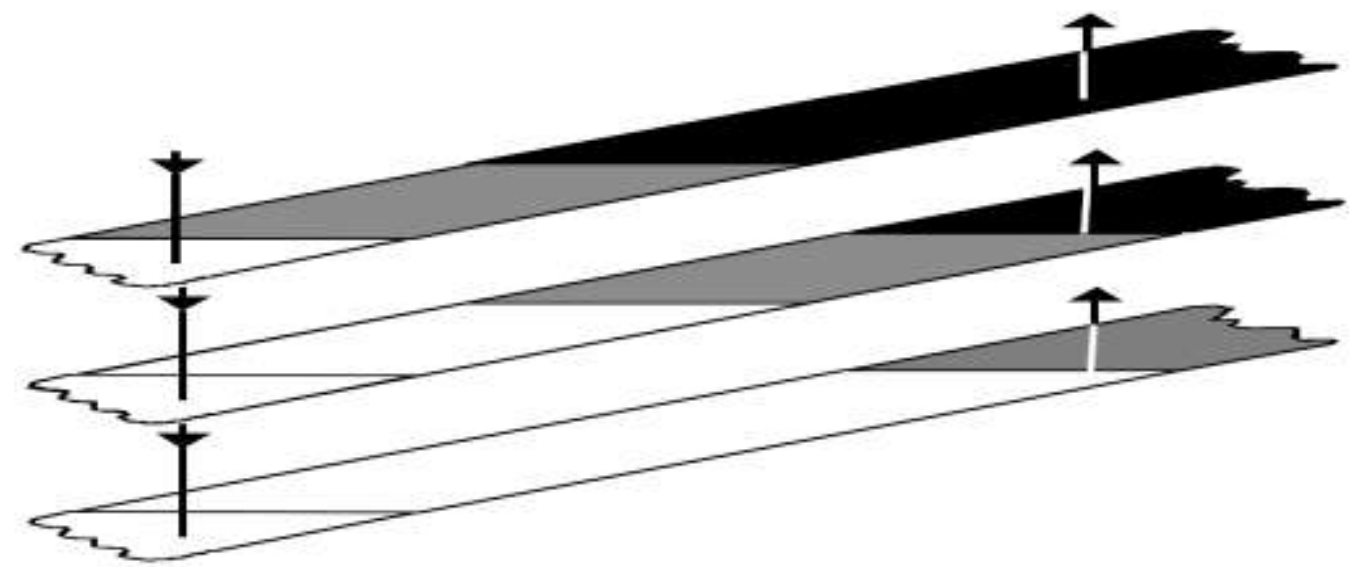

Figure 13. Oil displacement process.

permeability of oil and water increases and decreases, respectively (Liu et al., 2012). Actual core flooding experiments where nanoparticles were injected in real cores found that recovery of oil can increase from 5 up to about $20 \%$ in some cases (Liu et al., 2012; Karimi et al., 2012; Ogolo et al., 2012; Ju and Fan, 2009).

Ju et al. (2006) developed simulations to analyze wettability alterations caused by nanoparticles. They analyzed the effect of different physical and chemical properties of the nanoparticles, such as polymer coating, contact angle, and size in terms of empirical coefficients (Ju and Fan, 2009; Ju et al., 2006). They report that both permeability and porosity of the core decrease with injection of nanoparticles, and the decrease in permeability is more significant than porosity. However, the relative permeability of oil increases due to wettability alteration. Based on their simulations, oil recovery can be improved through wettability alteration by up to $20 \%$ when a high concentration of nanoparticle is injected. At the same time, increasing nanoparticle concentration leads to greater reductions in permeability. Therefore, they suggest an optimum concentration of nanoparticle (2 to $3 \%$ ) for injection into the core.

\section{TRANSPORT OF PNPS INPOROUS MEDIA}

The sections above focused on the properties of PNPs that can improve oil recovery. However, nanoparticles must also be able to propagate deep into the reservoir to assist oil displacement. Previous studies have reported challenges in the transport of nanoparticles through porous media (Zhan et al., 2008; Liu et al., 2005; Phenrat et al., 2008; Yang et al., 2007; Schrick et al., 2004). Nanoparticles coated with various polymers including polyacrylic acid (Kanel et al., 2008; Saleh et al., 2007; Phenrat et al., 2009; Hydutsky et al., 2007; Schrick et al., 2004; Ditsch et al., 2005; Saleh et al., 2005), cellulose (He et al., 2007), starch (He and Zhao, 2005), and surfactants (Quinn et al., 2005; Alessi and Li, 2001; Kanel et al., 2007) have been studied. In this section, a critical review of the mechanisms affecting transport of nanoparticles through porous media and current challenges are presented.

\section{Mechanisms of nanoparticle transport through porous media}

Three mechanisms primarily affect propagation of nanoparticles in porous media: physical filtration, solution chemical stability, and adsorption on the rock/porous media surface. Each of these is discussed separately below.

\section{Physical filtration}

Physical filtration occurs when the particles are larger than some of the pores in the porous media. This may even occur for well-dispersed (non-aggregated) nanoparticles in case of injection in low-permeability rocks, such as tight sandstones.

For non-aggregated nanoparticles, the size, shape and aspect ratio of the particle are relevant parameters that can affect filtration. The particle size-distribution is also important since filtration may be initiated with the larger particles. This can, in turn, cause further filtration due to decrease in the size of the pores after initial filtration (Baez et al., 2012). In the case of PNPs, both nanoparticles and polymeric coatings can be polydisperse.

\section{Solution and chemical stability of PNPs}

By solution and chemical solution stability, we refer to the solubility and dispersibility of nanoparticles. In the 
presence of high salinity and hardness (which is often the case in oil reservoirs), poor chemical stability can lead to aggregation or precipitation of nanoparticles. From the molecular viewpoint, both Van der Waals and hydrophobic attractions can result in precipitation and aggregation. Polymeric coatings on nanoparticles can potentially inhibit aggregation by providing electrostatic or steric repulsions (Hamedi Shokrlu and Babadagli, 2011). Different polyelectrolytes, such as poly(acrylic acid), poly(vinyl pyrrodine), poly(styrene sulfonate), and bilayers of ionic surfactants have been used to provide electrostatic repulsion between nanoparticles (Ersenkal et al., 2011; Yang et al., 2007; Yu et al., 2010; Bagaria et al., 2013). The challenge with these types of coatings is that they are usually highly $\mathrm{pH}$-dependent. Salinity and the presence of divalent ions can also affect the stability of PNPs. Some of these polymers [e.g., poly(vinyl pyrrodine)] can actually stabilize the nanoparticles in high salinity brines; however, they may cause the nanoparticles to readily adsorb to the rock surfaces. Yan et al. (2012) studied the effect of salinity (based on $\mathrm{KCl}$ ) on stability of a polyelectrolyte-coated PNP, and Bagaria et al. (2013) conducted a comprehensive study on the effects of salinity (based on $\mathrm{NaCl}$ ) and $\mathrm{Ca}^{+2}$ concentration on nanoparticles coated with different polyelectrolytes. Also, Kim et al. (2012) studied the effect of $\mathrm{pH}$ and clay minerals on the stability of nanoparticles coated with both low molecular weight and high molecular weight polyelectrolytes (with negative charges). The stability of PNPs with polyelectrolyte polymer coatings is found to depend on the $\mathrm{pH}$, and to be adversely affected by increases in salinity and divalent ion concentrations.

Ionic surfactants have also been used to stabilize nanoparticles (Quinn et al., 2005; Alessi and Li, 2001; Kanel et al., 2007). However, as discussed above, stabilization of nanoparticles using surfactants is sensitive to the concentration ratio of surfactant to nanoparticle. At low concentration ratios of surfactant to nanoparticle, a monolayer of surfactant is adsorbed on the nanoparticle surface, making it hydrophobic, but if a bilayer of surfactant adsorbs to the nanoparticle, it can lead to more chemical stabilization due to electrostatic repulsion.

Some researchers have used long-chain polymers such as cellulose, starch, or polyacrylamide, as a coating on the surface of nanoparticles to stabilize them in the solution (He et al., 2007; He and Zhao, 2005; Hamedi and Babadagli, 2011; Cirtiu et al., 2011). This type of polymer coating leads to repulsion between nanoparticles based on steric inhibition and entropic effects. However, they have not been successfully shown to stabilize the nanoparticles at high salinities present in many reservoirs due to the poor solubility of the polymers under these conditions. Nanoparticles can also be coated with a combination of polymers to provide both providing steric inhibition and electrostatic repulsion to optimize the stabilization and adsorption (Baez et al., 2012).
Cirtiu et al. (2011) compared the stability of PNPs with the polymeric layer either post-grafted to a premade nanoparticle or through pre-grafting, in which nanoparticle was synthesized while grafting polymers to the surface. They found that in most of the cases pregrafted samples led to a more stable PNP than the case of post-grafted PNPs.

Another factor to consider is that PNPs may behave differently and even have different sizes under static and dynamic conditions (Ersenkal et al., 2011). Ersenkal et al. (2011) investigated the size of poly(acrylic acid)-coated iron nanoparticles in static (in solution) and dynamic conditions (passed through a porous medium). They found that the nanoparticle size appeared to depend on nanoparticle solution concentration in dynamic tests but not static measurements. In dynamic tests, they found retardation in nanoparticle propagation for initial nanoparticle concentrations lower than $600 \mathrm{mg} / \mathrm{L}$ (Figure 14). They hypothesized that these results reflect forces and torques acting on nanoparticles in a dynamic test that are absent in a static one and that these forces are most significant in the areas of flow convergence in porous media that favor nanoparticle filtration or particle aggregation (Bradford and Torkzaban, 2008). This result highlights the complexity of the effects of dynamic factors (such as flow rate, permeability, etc.) on effective size of the nanoparticles and questions the validity of static measurements to determine the chemical stability of nanoparticles under dynamic conditions. Hamedi Shokrlu and Babadagli have examined the effects of various dynamic parameters (Hamedi and Babadagli, 2011) on the transport of nanoparticles through porous media and found that for the system of their study, higher injection rates can lead to lower retardation of nanoparticles. More studies are needed in this area.

\section{Adsorption on the porous media}

Even for nanoparticles of appropriate size and shape and good stability in solution, adsorption onto solid surfaces may impede nanoparticle transport. Low adsorption of the injected chemicals on rock also improves the economics of the oil recovery process (ShamsiJazeyi et al., 2014). Prior work has shown that many of the polymer coatings which can stabilize nanoparticles in solution can also result in high adsorption and retardation of nanoparticles once injected into the porous media (Baez et al., 2012; Yang et al., 2007; Yu et al., 2010; Bagaria et al., 2013; Kim et al., 2012).

Electrostatic repulsions and reduced hydrophobichydrophobic interactions between PNPs and the rock surface can reduce nanoparticle adsorption. PNPs with a surface charge that matches that of the rock surface (Ersenkal et al., 2011; Bagaria et al., 2013; Kim et al., 2012) or that are less hydrophobic (Bagaria et al., 2013) may exhibit reduced adsorption. However, this is 

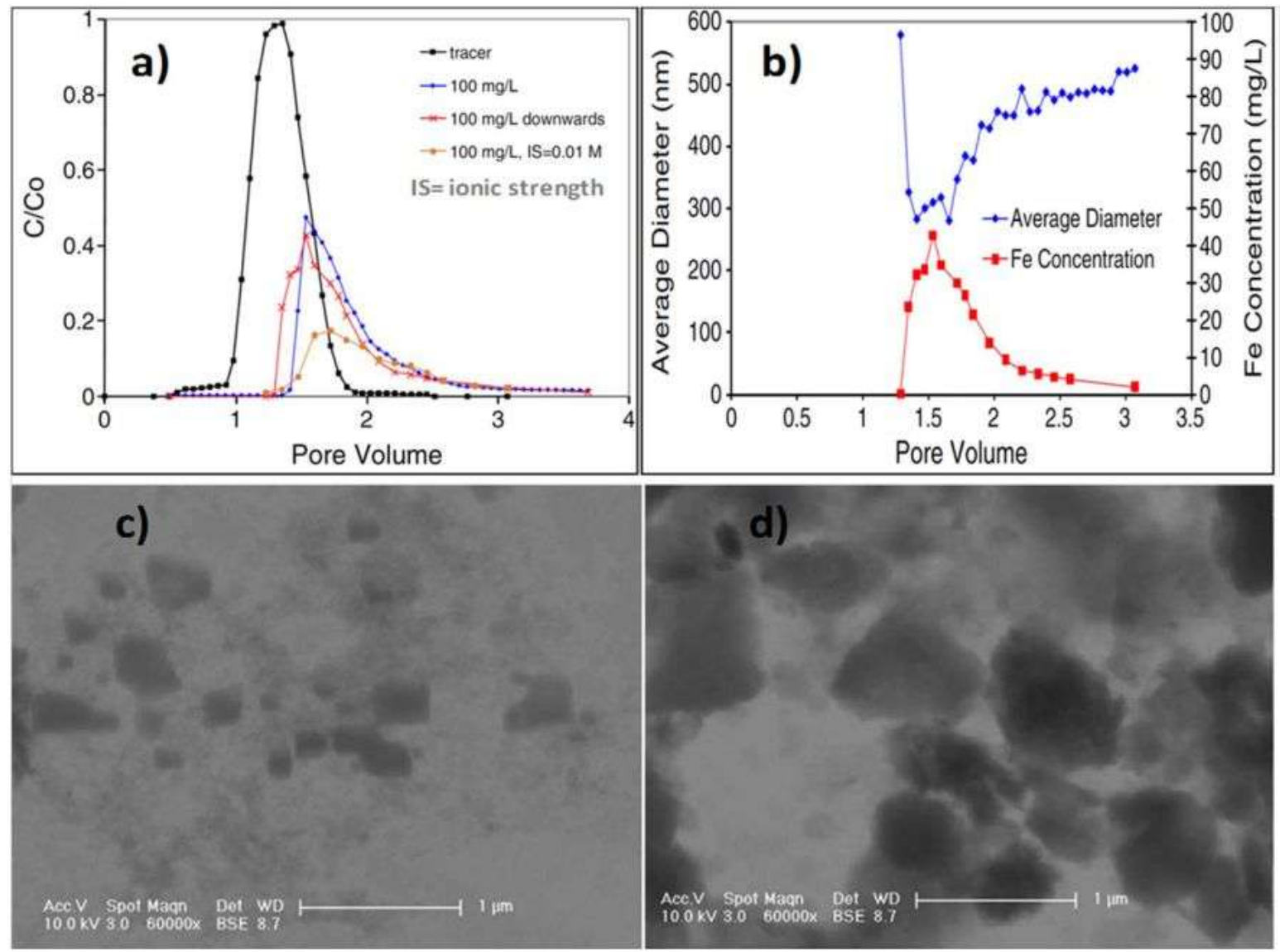

Figure 14. (a) The retardation of the poly(acrylic acid) coated iron nanoparticles in dynamic test; (b) the change in the effective size of nanoparticles as a function of injected pore volume; (c) ESEM images the size of nanoparticle before propagation through porous media; (d) the size of nanoparticle after propagation through porous media.

challenging considering the different salinities, divalent ion concentrations, and $\mathrm{pH}$ values that must be considered. Further, adsorption should be reduced while maintaining the nanoparticle properties favorable to EOR. As an example, in the case of surfactant-coated nanoparticles, monolayer adsorption of surfactant can improve foam stability but also result in higher adsorption.

\section{INTERFACIAL TENSION MEASUREMENT}

The IFT between the equilibrated brine and oil phases was measured with the help of a spinning drop tensiometer. In cases where third phase micro-emulsion was found to exist, oil phase was taken near the middle phase for accurate measurement of the IFT. Optimal salinity was taken as the salinity of the system which gave the least IFT between the oil and the aqueous phase. It was always near the salinity where the middle phase microemulsion was present in the phase behavior studies. The subsequent wettability experiments were performed at the optimal salinity obtained from these measurements (Adibhatla and Mohanty, 2006).

\section{Effects of nanoparticles on IFT reduction}

Role of the surfactant is to lower the interfacial tension and to form an initial dispersion of air/water or oil/water in case of foam or emulsion, respectively. Once this dispersion is formed due to shear and a decreased amount of interfacial tension, the stability of foam/emulsion is augmented by adsorption of nanoparticles at the interface (Worthen et al., 2013). For example, usage of silica nanoparticles coated with a polyelectrolyte to stabilize oil-in-water emulsions has been reported. More recently, Saigal et al. (2010) reported stable oil-in-water emulsions using silica nanoparticles coated with a $\mathrm{pH}$ responsive polymer, and they found that the most stable emulsions were formed at lower polymer chain grafting densities. In addition, some researchers investigated about the effects of nanoparticles on IFT reduction on surfactant solutions (Al-Raoush and Willson, 2005). They claimed that the presence of nanoparticles changes rheological properties and increases the effect of surfactant solution on oil recovery processes. First of all, it changes interfacial tension value of surfactant/oil interface more effectively 
Table 2. Nano-particles effect on IFT reduction.

\begin{tabular}{cccccc}
\hline \multicolumn{2}{c}{ Concentration (ppm) } & & \multicolumn{2}{c}{ Concentration (ppm) } & IFT (10-3 N/m) \\
\cline { 1 - 1 } \cline { 5 - 6 } $\begin{array}{c}\text { Sodium dodecyl } \\
\text { sulfate (SDS) }\end{array}$ & Nanoparticles & IFT (10-3 N/m) & $\begin{array}{c}\text { Dodecyl trimethylammonium } \\
\text { bromide (C12TAB) }\end{array}$ & Nanoparticles & \\
\hline 2000 & 0 & 16 & 3000 & 0 & 18.4 \\
2000 & 100 & 3.1 & 3000 & 100 & 5.4 \\
\hline
\end{tabular}

Source: Mohajeri et al. (2015).

(Munshi et al., 2008). Observed reduction of interfacial tension is the result of nanoparticles presence at the interfacial layers. In low concentrations of nanoparticles, they are attached to the liquid surface and due to absorption process surface tension decreases. However, in high concentrations, the nanoparticles nearly completely remove the surfactant from the bulk aqueous phase and there is no free surfactant available in the bulk. Thus, for nanoparticles in low concentrations the interfacial tension of the dispersion is determined by a mixed layer composed of attached nanoparticles and surfactant adsorbed at the liquid interface (Ravera et al., 2006). Accordingly, the interfacial tensions values were determined in different states. All reported interfacial tension values were measured by a drop shape tensiometer DSA30 of Kruss company. Pendant dropmethod based on the Laplace equation which describes relationship between the difference in pressure and interfacial tension was selected for our purpose. The results are shown in Table 2. As can be seen, nanoparticles decreased surface tension by $70 \%$ when used with a SDS concentration of $2000 \mathrm{ppm}$, while the figure for C12TAB was about $81 \%$.

In addition, ZRSL3000 solution, which was chosen before as an optimum concentration, showed an IFT value of $17.1(103 \mathrm{~N} / \mathrm{m})$. Seemingly, although this amount almost showed a same amount compared to both surfactants alone, it is by far more than nanoparticles/surfactant value. This means that nanoparticles along with surfactants can strongly decrease the interfacial tension of oil and water, which can lead to more stable emulsions and justify the enhancement of oil recovery. In this regard, SDS showed better performance than C12TAB when used either alone or with nanoparticles (Mohajeri et al., 2015). Nanoparticles form a mixed layer with surfactants at the interface between the injected fluid and oil. This results in increasing the interface consequently makes a considerable contribution to reducing IFT. This means that capillary forces considerably decrease and capillary number will strongly be increased (Rosen et al., 2005). In fact, both nanoparticles and surfactants help each other to remain stable and to contribute to keeping the formed emulsions stable. The presence of suspended nanoparticles in the solution increases sedimentation stability, because surface forces easily counterbalance the force of gravity. In addition, it is obvious that surfactants contribute to the stability of nanoparticles and emulsions to decrease IFT (Suleimanov et al., 2011; Qiu, 2010).

The influences of hydrophilic and slightly hydrophobic silica nanoparticles on sodium dodecyl sulfate anionic surfactant properties were investigated for enhancing oil recovery purpose. Surfactant interfacial and adsorption behaviors were investigated in the presence of nanoparticles. Considerably stable nanoparticle suspensions were obtained adding low amounts of sodium dodecyl sulfate. Opposing interfacial properties were observed for low to high surfactant concentrations for both hydrophilic and hydrophobic nanoparticleaugmented solutions. The inclusion of nanoparticles had a negligible influence on the oil/water interfacial tension at very low surfactant concentrations. However, surfactant efficiency was rather significantly improved at higher sodium dodecyl sulfate concentrations up to about $\mathrm{CMC}$ after which the oil/water interfacial tension began to grow. The interfacial tension eventually reached a constant value greater than the one obtained by the sole surfactant solution of the same concentration. Table 3 summarizes IFT of these surfactants with different nano concentration (Barati et al., 2014).

The results showed consistency with a relatively low deviation. The contact angle and interfacial tension (IFT) were measured and analyzed to determine the possible displacement mechanism. It was observed that the nanofluid rendered the quartz plate more water-wet in both wettability systems, and the presence of hydrophilic nanoparticles at a $0.05 \mathrm{wt} \%$ concentration was effective in altering the wettability between 15 and $33 \%$. The presence of NPs did not significantly reduce the IFT between the oleic- and aqueous-phase. Therefore, wettability alteration plays a more dominant role in the possible oil displacement mechanism using nano-EOR (Cheraghian, 2015). $\mathrm{SiO}_{2}$ nano-powder is a new type of augmented injection agent that has the ability of stronger hydrophobicity and lipophilicity, and can be absorbed on the rock surface leading to changes in the rock wettability level. It can be classified into two types: lipophobic and hydrophilic polysilicon nanoparticle (LHPN) and hydrophobic and lipophilic polysilicon nanoparticle (HLPN) (Ju and Fan, 2009; Suleimanov et al., 2011). On the other hand, it can reduce the interfacial tension (IFT) between two phases, enhance oil effective permeability and reduce injection pressure and augment injection rate 
Table 3. IFT of these surfactants with different nano concentration.

\begin{tabular}{ccccc}
\hline \multicolumn{2}{c}{ Concentration (ppm) } & & \multicolumn{2}{c}{ Interfacial tension ( dyne/cm) } \\
\cline { 1 - 2 } Surfactant & Nanoparticle & & Surfactant solution & Nanoparticle- augmented surfactant solution \\
\hline 500 & 1000 & & 7.43 & 3.71 \\
500 & 2000 & & 7.43 & 4.64 \\
1000 & 1000 & & 3.53 & 2.59 \\
1000 & 2000 & & 3.53 & 2.76 \\
2000 & 1000 & 2.60 & 1.87 \\
2000 & 2000 & 2.60 & 2.42 \\
4000 & 1000 & 2.90 & 3.64 \\
4000 & 2000 & 2.90 & 4.74 \\
6000 & 1000 & 2.85 & 4.26 \\
6000 & 2000 & 2.85 & 4.64 \\
\hline
\end{tabular}

Source. Barati et al. (2014).
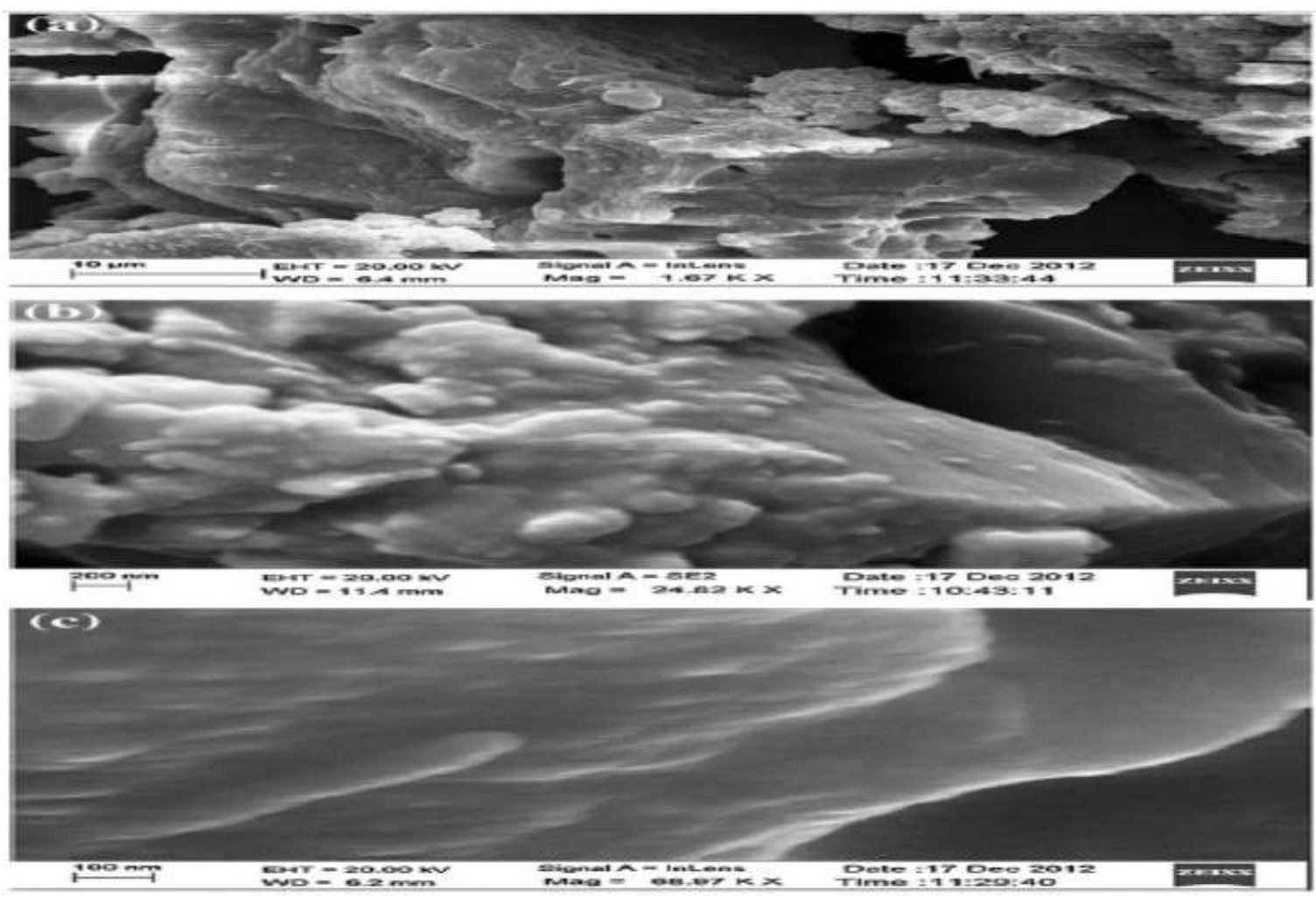

Figure 15. The SEM images of core plug after flooding with $0.01 \%$.

(Wang et al., 2010). Ehtesabi et al. (2015) researched about nano $\mathrm{TiO}_{2}$ on heavy oil recovery. Their results showed that $\mathrm{TiO}_{2}$ nanoparticles do not change significantly the viscosity and the interfacial tension. SEM images from the entrance side of the core plug after flooding test with $0.01 \% \mathrm{TiO}_{2}$ nanoparticles confirm the coating of the rock surface with $\mathrm{TiO}_{2}$ nanoparticles (Figure 15). The capability of hydrophilic and slightly hydrophobic silica nanoparticles to improve surfactant performance was explored. Prior to flooding experiments, the effects of nanoparticle on surfactant properties were investigated. The results showed that interfacial tension between nanoparticle-augmented surfactant solution and oil starts with a rapid decrease in low surfactant concentration and follows an increase at higher concentrations. Surfactant adsorption on rock surface 
was generally reduced in the presence of nanoparticle and this reduction was much more considerable for hydrophobic particles in all surfactant concentrations (Zargartalebi et al., 2015). A systematic study of hydrophilic metal oxide nanoparticles (NPs) for EOR purposes was performed, and the stability of metal oxidebased nanofluids was successfully improved by adding polyvinylpyrrolidone at $1 \mathrm{wt} \%$. The contact angle, interfacial tension (IFT) and effluent were measured and analysed in the displacement mechanism observations. It was observed that all nanofluids rendered the quartz plate more water-wet, and the $\mathrm{TiO}_{2}$-based nanofluid was the most effective wettability-altering fluid. This result is consistent with and proportional to the additional oil recovery from the core flood experiment. The particle adsorption during the transport process was identified from the effluent analysis. The presence of nanoparticles reduced the IFT between the oleic phase and aqueous phase as did the presence of polyvinylpyrrolidone as dispersant, but the degree of IFT reduction is not proportional to the additional oil recovery. The lowest IFT was achieved by metal oxide nanoparticles even though this material does not have the lowest $\mathrm{pH}$. The additional oil recovery due to silica-based nanofluid is greater than that of brine with polyvinylpyrrolidone solution, even though the silica-based nanofluid has a higher IFT than the brine with polyvinylpyrrolidone solution (Hendraningrat and Zhang, 2015). A systematic study of hydrophilic metal oxide nanoparticles (NPs) for EOR purposes was performed, and the stability of metal oxide based nanofluids was successfully improved by adding polyvinylpyrrolidone at $1 \mathrm{wt} \%$. Structure of PVP is shown in Figure 16. Hydrophilic metal oxide nanoparticles (Figure 17).

\section{CONCLUSION}

Nano particles can enhance the function ability of the stimulation fluids due to easy access of the nanos into the oil-water interface to reduce the IFT between the oil and the water and enhance the oil production (Amanullah and Al-Tahini, 2009).

Nanotechnology has the potential to have a positive effect on the chemical EOR process. The aims of this paper were firstly to compile an up-to-date data base for implemented nano chemical injection projects reported in the literature over the last 15 years. Altogether, nanotechnology can be an effective enhancement option for an oil recovery method in an oil reservoir which is technically sensitive to the chemical recovery method. Although the future of nanotechnology is completely uncharted territory, certainly nanotechnology will revolutionize the oil industry in several important ways.

A review of the effect of NPs and PNPs on wettability for enhanced oil recovery processes has been presented. Several cases as well as laboratory studies were

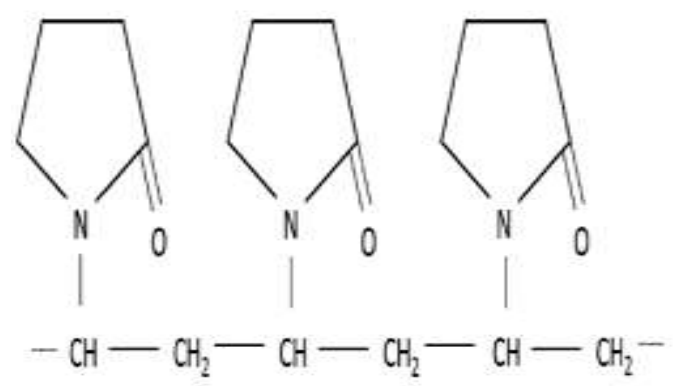

Figure 16. Chemical structure of PVP (Folttmann and Quadir, 2008) nanoparticles a 10 $\mathrm{nm}$ scale and b $200 \mathrm{~nm}$ scale and c $100 \mathrm{~nm}$ scale (Ehtesabi et al., 2015).

discussed.

\section{SUMMARY OF CHALLENGES AND DIRECTIONS FOR FUTURE RESEARCH}

Nanoparticle-based technologies are promising for EOR processes and, in the case of bright water polymeric nanoparticles, have been field-tested for improving oil recovery. Polymer coatings can potentially offer significant advantages in terms of tuning nanoparticle surface properties, stability, and responsiveness, but more studies are needed to understand the potential of NPs and PNPs for EOR. Below, we prioritize areas of emphasis that need to be addressed for the eventual implementation of PNPs in EOR processes.

First, for the use of PNPs to improve mobility control, the energy required to stabilize a foam or emulsion should be commensurate with the energy required for injection into cores, with typical flow rates on the order of $10 \mathrm{ft} /$ day. The role of different types and functionalities of polymers should be investigated to reduce the energy required for adsorption of nanoparticles at the fluid-fluid interface as well as for foam/emulsion stability.

Second, the thermodynamics of polymer rearrangement on the surface of PNPs located at an interface remains poorly understood. Thermodynamic models that consider the effects of rearrangement of polymers at the interface on the energy and entropy of the foam and emulsion systems should be further explored.

Third, studies are lacking on the effect of different types of polymers as coatings on nanoparticles for wettability alteration. Polymers can have different effects on energy and entropy of the system (structural, electrostatic, hydrophobic, and other effects), which change the disjoining pressure near the inner contact line and change the rate of wettability alteration caused by such PNPs.

Polymer coatings that can facilitate NP and PNP propagation through a reservoir under harsh conditions, such as high salinity and high temperatures, are needed. 


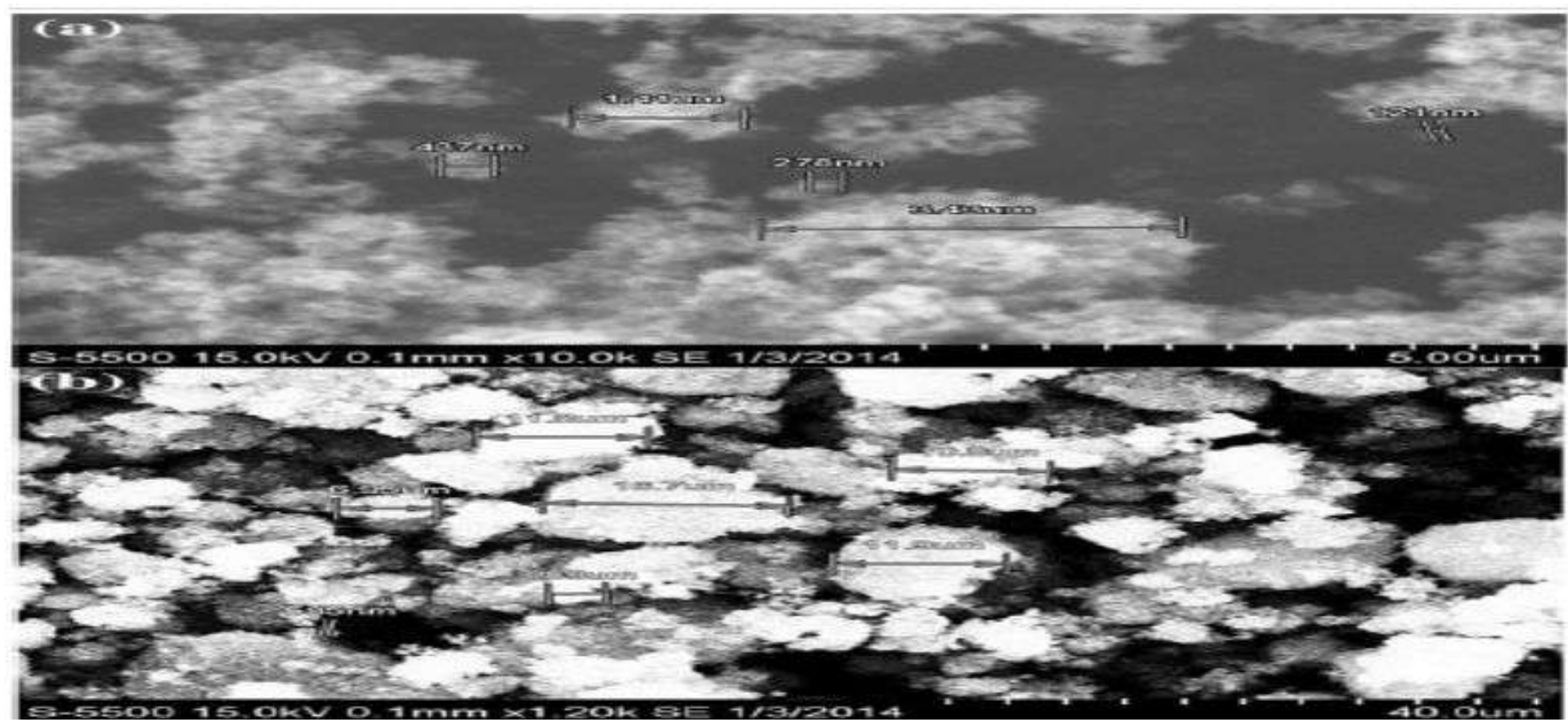

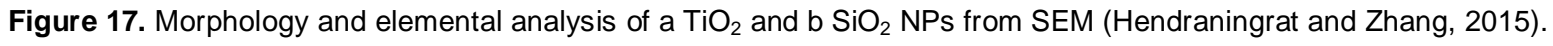

A proper stabilizing polymer coating is one that not only stabilizes the nanoparticle in both static and dynamic conditions, but also has maximum long-term chemical stability and minimum adsorption on the rock. Addressing these challenges may eventually lead to an optimized PNP polymer coating that minimizes the undesirable effects (adsorption, aggregation, etc.) and maximizes desirable effects such as increased viscosity, emulsion generation, and reduced interfacial tension under a variety of environmental conditions.

\section{REFERENCES}

Adibhatla, B., Mohanty, K. K. (2006) Oil recovery from fractured carbonatesby surfactant-aided gravity drainage: laboratory experimentsand mechanistic simulations. In: SPE 99773, The 2006 SPE/DOE Symposium on Improved Oil Recovery held in Tulsa,Oklahoma, USA, 22-26 April.

Akcora, P., Liu, H., Kumar, S. K., Moll, J., Li, Y., Benicewicz, B. C., Schadler, L. S., Acehan, D., Panagiotopoulos, A. Z., Pryamitsyn, V., Ganesan, V., Ilavskey, J., Thiyagarajan, P., Colby, R. H., Douglas, J. F. (2009). Anisotropic self-assembly of spherical polymer-grafted nanoparticles. Nat Mater, 8: 354-359.

Alessi, D. S., Li, Z. (2001). Synergistic effect of cationic surfactants on perchloroethylene degradation by zero-valent iron. Environ Sci Technol, 35: 3713-3717.

Al-Raoush, R. I., Willson, C. S. (2005). A pore-scale investigation of a multiphase porous media system. J Contam Hydrol, 77: 67-89.

Alvarez, N. J., Anna, S. L., Saigal, T., Tilton, R. D., Walker, L. M. (2012). Interfacial dynamics and rheology of polymer-grafted nanoparticles at air-water and xylene-water interfaces. Langmuir, 28: 8052-8063.

Amanullah M, Al-Tahini, A. M. (2009). Nanotechnology: Its Significance in Smart Fluid Development for Oil and Gas Field Application. SPE No. 126102-MS.

Aminzadeh-goharrizi, B., DiCarlo, D., Hyun Chung, D., Roberts, M., Bryant, S., Huh, C. (2012). Effect of Spontaneous Formation of Nanoparticle Stabilized Emulsion on the Stability of a Displacement in Society of Petroleum Engineers, SPE-154248-MS.

Aminzadeh-goharrizi, B., Huh, C., Bryant, S., DiCarlo, D., Roberts, M. (2012). Effect of nanoparticles on flow alteration during $\mathrm{CO}_{2}$ injection. In SPE Annual Technical Conference and Exhibition, SPE-154228MS.

Anderson, W. G. (1987). Wettability literature survey-Part 6: The effects of wettability on waterflooding. J PetTech, 39: 1605-1622.

Aoudia, M., Al-Shibli, M. N., Al-Kasimi, L. H., Al-Maamari, R., AlBemani, A. (2006). Novel surfactants for ultra low interfacial tension in a wide range of surfactant concentration and temperature. J Surfac Deterg, 9: 287-293.

Austad, T., Fjelde, I., Veggeland, K., Taugbol, K. (1994). Physicochemical principles of low tension polymer flood. J Petrol Sci Eng, 10: 255-269.

Baez, J., Ruiz, M., Faria, J., Harwell, J., Shiau, B., Resasco, D. (2012). Stabilization of Interfacially Active Nanohybrids/Polymer Suspensions and Transport through Porous Media. In Society of Petroleum Engineers, SPE-154052-MS

Bagaria, H. G., Neilson, B. M., Worthen, A. J., Xue, Z., Yoon, K. Y., Cheng, V., Lee, J. H., Velagala, S., Huh, C., Bryant, S. L., Bielawski, C. W., Johnston, K. P. (2013). Adsorption of iron oxide nanoclusters stabilized with sulfonated copolymers on silica in concentrated $\mathrm{NaCl}$ and $\mathrm{CaCl}_{2}$ brine. J Colloid Interface Sci, 398: 217-226.

Barati, N., Zargartalebi, M., Kharrat, R. (2014). Influences of hydrophilic and hydrophobic silica nanoparticles on anionic surfactant properties: interfacial and adsorption behaviors. J Pet Sci Eng, 119: 36-43.

Barnes, P. F., Tinker, G. E. (1985). Production Technology Experience in Michigan Waterfloods JPT. pp: 1446-58.

Binks, B. P., Kirkland, M., Rodrigues, J. A. (2008). Origin of stabilisation of aqueous foams in nanoparticle-surfactant mixtures. Soft Matter, 4: 2373-2382.

Binks, B. P., Rodrigues, J. A. (2007). Enhanced stabilization of emulsions due to surfactant-induced nanoparticle flocculation. Langmuir, 23: 7436-7439.

Bishan, J., Tailang, F., Mingxua, M. (2005). Enhanced oil recovery by uooding with hydrophilic nanoparticles. China Particuol, 4: 41-46.

Blanco, E., Lam, S., Smoukov, S. K., Velikov, K. P., Khan, S. A., Velev, O. D. (2013). Stability and viscoelasticity of magneto-pickering foams. Langmuir, 29, 10019-10027.

Boberg, T. C. (1988). Thermal Methods of Oil Recovery. Institut Fracais du Petrole Publications: Technip Edition, France.

Bondor, P. L. (1992). Applications of carbon dioxide in enhanced oil 
recovery. Energy Convers Manag, 33: 579-586.

Bradford, S. A., Torkzaban, S. (2008). Colloid transport and retention in unsaturated porous media: A review of interface-, collector-, and pore-scale processes and models. Vadose Zone J, 7: 667- 681.

Breuer, M. M., Robb I. D. (1972). Interactions between macromolecules and detergents. Chem Ind, 54: 530-535.

Briseno, A. L., Holcombe, T. W., Boukai, A. I., Garnett, E. C., Shelton, S. W., Fréchet, J. J. M., Yang, P. (2010). Oligo- and polythiophene/ZnO hybrid nanowire solar cells. Nano Lett, 10: 334340.

Brown, L. R. (2010). Microbial enhanced oil recovery (MEOR). Curr Opin Microbiol, 13: 316-320.

Buckley, J. S., Liu, Y. (1998). Some mechanisms of crude oil/brine/solid interactions. J Pet Sci Eng, 20: 155-160.

Buckley, J. S., Liu, Y., Monsterleet, S. (1998). Mechanisms of wetting alteration by crude oils. Soc Pet Eng J, 3: 54-61.

Cao, Y., Zhao, R., Zhang, L., Xu, Z., Jin, Z., Luo, L., Zhang, L., Zhao, S. (2012). Effect of electrolyte and temperatureon interfacial tensions of alkylbenzene sulfonate solutions. Energy Fuels, 26: 2175-2181.

Cayre, O. J., Chagneux, N., Biggs, S. (2011). Stimulus responsive coreshell nanoparticles: synthesis and applications of polymer based aqueous systems. Soft Matt, 7: 2211-2234.

Chang, S. H., Chung I. J. (1991). Effect of shear flow on polymer desorption and latex dispersion stability in the presence of adsorbed polymer. Macromolecules, 24: 567-571.

Chengara, A., Nikolov, A. D., Wasan, D. T., Trokhymchuk, A., Henderson, D. (2004). Spreading of nanofluids driven by the structural disjoining pressure gradient. J Colloid Interface Sci, 280: 192-

Cheraghian, G. (2015). An experimental study of a surfactant polymer for enhanced heavy-oil recovery usinga glass micromodel by adding nanoclay. J Pet Sci Tech, 33: 13-14.

Cheraghian, G. (2015). Effects of nanoparticles on wettability: a reviewon applications of nanotechnology in the enhanced oil recovery. Int J Nano Dimens, 6(5): 443-452.

Cheraghian, G., Khalili Nezhad, S. (2015), Effect of nanoclay on heavy oil recovery during polymer flooding. J Pet Sci Tech, 33: 9991007.

Cheraghian, G., Khalili Nezhad, S., Kamari, M., Hemmati, M., Masihi, M., Bazgir, S. (2014). Adsorption polymer on reservoir rock and role of the nanoparticles, clay and $\mathrm{SiO}_{2}$. Int Nano Lett, 4: 114-117.

Cheraghian, G., Khalili Nezhad, S., Kamari, M., Hemmati, M., Masihi, M., Bazgir, S. (2014). Effect of nanoclay on improved rheology properties of polyacrylamide solutions used in enhanced oil recovery. J Petrol Explor Prod Tech, 5: 189-196.

Cheraghian, G., Tardasti, S. (2012). Improved Oil Recovery by the Efficiency of Nano-particle in Imbibition Mechanism. 74th EAGE Conference and Exhibition incorporating EUROPEC.

Cirtiu, C. M., Raychoudhury, T., Ghoshal, S., Moores, A. (2011). Systematic comparison of the size, surface characteristics and colloidal stability of zero valent iron nanoparticles pre- and postgrafted with common polymers. Colloids Surf A, 390: 95-104.

Criag, F. F. Jr. (1971). The Reservoir Engineering Aspects of waterflooding, Monograph Series, SPE, Richardson, TX 3, Chap. 8.

Criag, F. F. Jr. (1973). Effect of Reservoir Description on Performance Predictions. Waterflooding, Reprint Series, SPE, Richardson. TX. 2a, 257-63.

Cui, Z. G., Cui, Y. Z., Cui, C. F., Chen, Z., Binks, B. P. (2010). Aqueous foams stabilized by in situ surface activation of $\mathrm{CaCO}_{3}$ nanoparticles via adsorption of anionic surfactant. Langmuir, 26: 12567-12574.

Cui, Z., Du, X., Pei, X., Jiang, J., Wang, F. (2012). Synthesis of didodecylmethylcarboxyl betaine and its application in surfactant.polymer flooding. J Surfac Deterg, 15: 685-694.

Cuiec, L. E. (1990). Evaluation of reservoir wettability and its effect on oil recovery. In: Morrow, N.R. (Ed.), Interfacial Phenomena in Oil Recovery. Marcel Decker, New York, 375-391.

DiCarlo, D. A., Aminzadeh, B., Roberts, M., Chung, D. H., Bryant, S. L., Huh, C. (2011). Mobility control through spontaneous formation of nanoparticle stabilized emulsions. Geophys Res Lett, 38: 1-5.

Dillan, K. W., Goddard, E. D., McKenzie, D. A. (1979). Oily soil removal from a polyester substrate by aqueous nonionic surfactant systems. J Am Oil Chem Soc, 56: 59-69.
Ditsch, A., Laibinis, P. E., Wang, D. I. C., Hatton, T. A. (2005). Controlled clustering and enhanced stability of polymer-coated magnetic nanoparticles. Langmuir, 21: 6006-6018.

Donaldson, E. C., Chilingarian, G. V., Yen, T. F. (1989). Enhanced Oil Recovery, II, Processes and Operations. Elsevier: New York, Newnes.

Dong, X., Xu, J., Cao, C., Sun, D., Jiang, X. (2010). Aqueous foam stabilized by hydrophobically modified silica particles and liquid paraffin droplets. Colloids Surf A: Physicochem Eng Aspects, 353: 181-188.

Downs H. H., Hoover P. D. (1989). Enhanced Oil Recovery by Wettability Alteration. ACS Symp Ser, 396: 577.

Du, K., Glogowski, E., Emrick, T., Russell, T. P., Dinsmore, A. D. (2010). Adsorption energy of nano- and microparticles at liquid-liquid interfaces. Langmuir, 26: 12518-12522.

Du, Y., Guan, L., (2004). Field -scale polymer flooding: lessons learnt and experiences gained during past 40 years. SPE 91787 presented at SPE international petroleum conference, Pubela, Mexico, 8-9 November.

Dwarakanath, V., Jackson, R. E., Pope, G. A. (2002). Influence of wettability on the recovery of NAPLs from alluvium. Environ Sci Tech, 36: 227-231.

Ehtesabi, H., Ahadian, M. M., Taghikhani, V. (2015). Enhanced heavy oil recovery using $\mathrm{TiO}_{2}$ nanoparticles: investigation of deposition during transport in core plug. Energy Fuel, 29(1): 1-8.

Engese, B. (2012). The Potential of Hydrophilic silica Nanoparticles for EOR Purposes: A Literature Review and an Experimental Study. Norway: Department of Petroleum Engineering and Applied Geophysics, Norwegian University of Science and Technology. Trondheim, Master thesis.

Ersenkal, D. A., Ziylan, A., Ince, N. H., Acar, H. Y., Demirer, M., Copty, N. K. (2011). Impact of dilution on the transport of poly(acrylic acid) supported magnetite nanoparticles in porous media. J Contam Hydrol, 126: 248-257.

Ershadi, M., Alaei, M., Rashidi, A., Ramazani, A., Khosravani, S. (2015). Carbonate and sandstone reservoirs wettability improvement without using surfactants for chemical enhanced oil recovery (CEOR). Fuel, 153: 408-415.

Esmaeilzadeh, P., Hosseinpour, N., Bahramian, A., Fakhroueian, Z., Arya, S. (2014). Effect of $\mathrm{ZrO}_{2}$ nanoparticles on the interfacial behavior of surfactant solutions at air.water and n-heptane.water interfaces. Fluid Phase Equilibria, 361: 289-295.

Espinoza, D., Caldelas, F., Johnston, K., Bryant, S., Huh, C. (2010). Nanoparticle-Stabilized Supercritical $\mathrm{CO}_{2}$ Foams for Potential Mobility Control Applications. In SPE Improved Oil Recovery Symposium, SPE-129925-MS.

Ferdous, S., loannidis, M. A., Henneke, D. E. (2012). Effects of temperature, $\mathrm{pH}$, and ionic strength on the adsorptionof nanoparticles at liquid.liquid interfaces. J Nanopart Res, 14: 850-855.

Folttmann, H., Quadir, A. (2008). Polyvinylpyrrolidone (PVP)—one of the most widely used excipients in pharmaceuticals: an overview. Drug Deliv Technol, 8(6): 22-27.

Garbin, V., Crocker, J. C., Stebe, K. J. (2012). Nanoparticles at fluid interfaces: Exploiting capping ligands to control adsorption, stability and dynamics. J Colloid Interface Sci, 387: 1-11.

Ghauri, W. K. (1976). Waterflood surveillance. Paper presented at the 23rd Annual South-western Petroleum Short Course, Lubbock.

Giraldo, J., Benjumea, P., Lopera, S., Cortés, F. B., Ruiz, M.A. (2013). Wettability alteration of sandstone cores by alumina-based nanofluids. Energy Fuels, 27: 3659-3665.

Goddard, E. D. (1986). Interactions between macromolecules and detergents. Colloids Surf, 1: 255-300.

Gong, H., Guiying, X., Zhu, Y., Wang, Y., Dan, W., Niu, M., Wang, L., Guo, H., Wang, H. (2009). Influencing factors on the properties of complex systems consisting of hydrolyzedpolyacrylamide/triton $\mathrm{x}$ $100 /$ cetyl trimethyl ammonium bromide: viscosity and dynamic interfacial tension studies. Energy Fuels. 23: 300-305.

Gonzenbach, U. T.; Studart, A. R.; Tervoort, E.; Gauckler, L. J. (2006) Ultrastable particle-stabilized foams. Angew Chem Int Ed, 45: 3526 3530.

Goolsby, J. L. (1965). The Relation of Geology to Fluid Injection in Permian Carbonate Reservoirs In West Texas. Paper presented at 
south-western Petroleum Short Course, Lubbock.

Guo, X. H., Li, D. W., Tian, J., Liu, Y.Z. (1999). Pilot test of xanthan gum flooding in Shengli oilfield. In: SPE 57294 presented at SPE Asia Pacific improved oil recovery conference, Kuala Lumpur.

Hamedi Shokrlu, Y., Babadagli T. (2010). Effects of nano sized metals on viscosity reduction of heavy oil/bitumen during thermal applications, Candian Unconvential Resources \& International Petroleum Conference Held in Calgary, Alberta, Canda, 19-21 October.

Hamedi Shokrlu, Y., Babadagli, T. (2011). Transportation and Interaction of Nano and Micro Size Metal Particles Injected to Improve Thermal Recovery of Heavy-Oil. In Society of Petroleum Engineers, SPE-157094-MS.

Hatiboglu, C., Babadagli, T. (2006). Primary and secondary oil recovery from different-wettability rocks by countercurrent diffusion and spontaneous imbibition. SPE/ DOE Symposium on Improved Oil Recovery, Tulsa, Oklahoma (paper SPE 94120).

He, F., Zhao, D. (2005). Preparation and characterization of a new class of starch-stabilized bimetallic nanoparticles for degradation of chlorinated hydrocarbons in water. Environ Sci Technol, 39: 33143320.

He, F., Zhao, D., Liu, J., Roberts, C. B. (2007). Stabilization of Fe-Pd nanoparticles with sodium carboxymethyl cellulose for enhanced transport and dechlorination of trichloroethylene in soil and groundwater. Ind Eng Chem Res, 46: 29-34.

Heller J. P. (1994). $\mathrm{CO}_{2}$ Foams in Enhanced Oil Recovery. J. Am. Chem. Soc., 242, 201-234.

Hematpour, H., Arabjamloei, R., Nematzadeh, M., Esmaili, H., Mardi, M. (2012). An experimental investigation of surfactant flooding efficiency in low viscosity oil using a glass micromodel. Ener Sour Part A Recov Utiliz Environ Effect, 34: 1745-1758.

Hendraningrat, L., Engeset, B., Suwarno, S., Torsaeter, O. (2012). Improved oil recovery by nanofluids flooding: An experimental study. In: SPE Kuwait City, Kuwait.

Hendraningrat, L., Li, S., Torsaeter, O. (2013). A corefluid investigation of nanofluid enhanced oil recovery. J Petrol Sci Eng, 111: 128-138.

Hendraningrat, L., Li, S., Torsaeter, O. (2013). Enhancing oil recovery of low -permeability berea sandstone through optimised nanofluids concentration. In: SPE enhanced oil recovery conference, Kuala Lumpur, Malaysia.

Hendraningrat, L., Torsaeter, $O$. (2014). Metal oxide based nanoparticles: revealing their possibility to enhance the oil recovery at different wettability systems. Appl. Nano Sci. Springer.

Hendraningrat, L., Zhang, J. (2015). Polymeric nanospheres as a displacement fluid in enhanced oil recovery. Appl. Nano Sci, 5(8): 1009-1016.

Hirasaki, G., Miller, C. A., Puerto, M. (2011). Recent advances in surfactant EOR. Soc Pet Eng J, 16: 889.

Hirasaki, G., Zhang, D. (2004). Surface chemistry of oil recovery from fractured, oil-wet, carbonate formations. Soc Pet Eng J, 9: 151.

Holbert, D. R., Zeito, G. A. (1960). A Study of Reservoir Characteristics in Three Problem Waterfloods. Prod. Monthly. pp: 20-26.

Hornof, V., Morrow, N. R. (1987). Gravity effects in the displacement of oil by surfactant solution. SPE Paper No. 13573. SPE. Reserv. Eng, 2: 627-633.

Hwang, C. C., Wang, L.; Lu, W., Ruan, G. D.; Kini, G. C., Xiang, C. S., Samuel, E. L. G., Shi, W., Kan, A. T., Wong, M. S., Tomson, B., Tour, J. M. (2012). Highly stable carbon nanoparticles designed for downhole hydrocarbon detection. Energy Environ Sci, 5: 8304-8309.

Hydutsky, B. W., Mack, E. J., Beckerman, B. B., Skluzacek, J. M., Mallouk, T. E. (2007). Optimization of nano- and microiron transport through sand columns using polyelectrolyte mixtures. Environ Sci Technol, 41: 6418-6424.

Isa, L., Amstad, E., Schwenke, K., Del Gado, E., Kröger, M., Reimhult, E. (2011). Adsorption of core-shell nanoparticles at liquid-liquid interfaces. Soft Matter, 7: 7663-7675.

Jadhunandan, P. P., Morrow, N. R. (1995). Effect of wettability on waterûood recovery for crude-oil/brine/rocksystems. SPE Reservoir Eng, 10: 40-46.

Johannesen, E. B., Graue A., (2007). Mobilization of remaining oil.Emphasis on capillary number andwettability. Int. Oil Conf. Exhibition in Mexico, Veracruz, Mexico (paper SPE 108724).
Johannesen, E., Graue A., 2007. Systematic investigation of waterflood reducing residual oil saturations by increasing differential pressures at various wettabilities. Offshore Europe, Aberdeen, Scotland, UK. (paper SPE 108593).

Joonaki, E., Ghanaatian, S., (2014). The application of nanofluids for enhanced oil recovery: Effects on interfacial tension and coreflooding process. J Pet Sci Tech, 32: 2599-2607.

Ju, B., Fan, T. (2009). Experimental study and mathematical model of nanoparticle transport in porous media. Powder Technol, 192: 195202.

Ju, B., Fan, T., Ma, M. (2006). Enhanced oil recovery be flooding with hydrophilic nanoparticles. China Particuol, 4: 41-46.

Ju, B., Luan, Z., Wu, Z., Lü, G., (2001). A study of removal of organic formation damage by experiments and modeling approaches. Proceedings of the SPE Asia Pacific Oil and Gas Conference and Exhibition. Jakarta, Indonesia.

Ju, B., Tailing, F., Mingxue, M. (2006). Enhanced oil recovery by flooding with hydrophilic nanoparticles. China Partic, 4: 41-46.

Kanel, S. R., Goswami, R. R., Clement, T. P., Barnett, M. O., Zhao, D. (2008). Two dimensional transport characteristics of surface stabilized zero-valent iron nanoparticles in porous media. Environ Sci Technol, 42, 896-900.

Kanel, S. R., Nepal, D., Manning, B., Choi, H. (2007). Transport of surface-modified iron nanoparticle in porous media and application to arsenic(III) remediation. J Nanopart Res, 9: 725-735.

Kanj, M. Y., Funk, J. J., Al-Yousif, Z. (2009). Nanofluid coreflood experiments in the ARAB-D, SPE Saudi Arabia Section Technical Symposium and Exhibition, Al Khobar, Saudi Arabia.

Kao, R. L., Wasan, D. T., Nikolov, A. D., Edwards, D. A. (1989). Mechanisms of oil removal from a solid surface in the presence of anionic micellar solutions. Colloids Surf, 34: 389-398.

Karimi, A, Fakhroueian, Z, Bahramian, A, PourKhiabani, N., Darabad, J. B., Azin, R., Arya, S. (2012). Wettability alteration in carbonates using zirconium oxide nanofluids: EOR implications. Energy Fuels, 26: 1028-1036.

Kim, H. J., Phenrat, T., Tilton, R. D., Lowry, G. V. (2012). Effect of kaolinite, silica fines and $\mathrm{pH}$ on transport of polymer-modified zero valent iron nano-particles in heterogeneous porous media. J Colloid Interface Sci, 370, 1-10.

Kim, J., Green, P. F. (2010). Phase behavior of thin film brush-coated nanoparticles/homopolymer mixtures. Macromolecules, 43: 15241529.

Kondiparty, K., Nikolov, A. D., Wasan, D., Liu, K. L. (2012). Dynamic spreading of nanofluids on solids. Part I: experimental. Langmuir, 28: 14618-14623.

Kowalewski, E., Holt, T., Torsaeter, O. (2002), Wettability alterations due to an oil soluble additive. J Petrol Sci Eng, 33: 19-28.

Kumar, S. K., Jouault, N., Benicewicz, B., Neely, T. (2013) Nanocomposites with Polymer Grafted Nanoparticles. Macromolecules, 46: 3199-3214.

Kumari, A., Yadav, S. K., Yadav, S. C. (2010). Biodegradable polymeric nanoparticles based drug delivery systems. Colloids Surf B Biointerface, 75: 1-18.

Lake, L. W. (1989). Enhanced Oil Recovery. Prentice-Hall, Inc., Upper Saddle River, New Jersey.

Lazar, I., Petrisor, I. G., Yen, T. F. (2007). Microbial enhanced oil recovery (MEOR). Pet Sci Technol, 25: 1353-1366.

Le, N., Pham, D. K., Le, K. H., Nguyen, P. T. (2011). Design and screening of synergistic blends of $\mathrm{SiO}_{2}$ nanoparticles and surfactants for enhanced oil recovery in high-temperature reservoirs. Adv Nat Sci: Nanosci Nanotech, 2: 45-49.

Li, Q., Kang, C., Wang, H., Liu, C., Zhang, C. (2002). Application of microbial enhanced oil recovery technique to Daqing Oilfield Biochem Eng J, 11: 197-199.

Li, X., Shamsi Jazeyi, H., Pesek, S. L., Agrawal, A., Hammouda, B., Verduzco, R. (2014). Thermoresponsive PNIPAAM bottlebrush polymers with tailored side-chain length and end-group structure. Soft Matter, 10: 2008-2015.

Li, X., Ying, Z., Jia, Y., Liu, X., Yang, T., Ma, L. (2012). Application of nanosphere deep control and displacement technology in Chanqing oil field. Oil Field Chem, 29: 13-16.

Li, Z. F., Ruckenstein, E. (2004). Water-soluble poly(acrylic acid) 
grafted luminescent silicon nanoparticles and their use as fluorescent biological staining labels. Nano Lett, 4: 1463-1467.

Limage, S., Kräugel, J., Schmitt, M., Dominici, C., Miller, R., Antoni, M. (2010). Rheology and structure formation in diluted mixed particle-surfactant systems. Langmuir, 26: 16754-16761.

Lindman, B., Thalberg, K., Goddard, E. D., Ananthapadmanabhan, K. P. (1993). Interactions of Surfactants with Polymers and Proteins, CRC Press, Boca Raton. 203-276.

Liong, M., Lu, J., Kovochich, M., Xia, T., Ruehm, S. G., Nel, A. E., Tamanoi, F., Zink, J. I. (2008). Multifunctional inorganic nanoparticles for imaging, targeting, and drug delivery. ACS Nano, 2: 889-896.

Liu, K. L., Kondiparty, K., Nikolov, A. D., Wasan, D. (2012). Dynamic spreading of nanofluids on solids part II: modeling. Langmuir, 28, 16274-16284.

Liu, Y., Majetich, S. A., Tilton, R. D., Sholl, D. S., Lowry, G. V. (2005). TCE dechlorination rates, pathways, and efficiency of nanoscale iron particles with different properties. Environ Sci Technol, 39: 13381345.

Lu, A. H., Salabas, E. L., Schüth, F. (2007). Magnetic nanoparticles: Synthesis, protection, functionalization, and application. Angew Chem Int Ed, 46: 1222-1244.

Maghzi, A, Mohebbi, A, Kharrat, R, Ghazanfari, M. H. (2011). Porescale monitoring of wettability alteration by silica nanoparticles during polymer flooding to heavy oil in a five-spot glass micromodel. Transp Porous Med, 87: 653-664.

Maillard, D., Kumar, S. K., Fragneaud, B., Kysar, J. W., Rungta, A., Benicewicz, B. C., Deng, H., Brinson, L. C., Douglas, J. F. (2012). Mechanical properties of thin glassy polymer films filled with spherical polymer-grafted nanoparticles. Nano Lett., 12: 3909-3914.

Maillard, D., Kumar, S. K., Rungta, A., Benicewicz, B. C., Prud'homme, R. E. (2011). Polymer-grafted-nanoparticle surfactants. Nano Lett, 11, 4569-4573.

Mandal, T. K., Fleming, M. S., Walt, D. R. (2002). Preparation of polymer coated gold nanoparticles by surface-confined living radical polymerization at ambient temperature. Nano Lett, 2: 3-7.

Matar, O. K., Craster, R. V., Sefiane, K. (2007). Dynamic spreading of droplets containing nanoparticles. Phys. Rev. E, 76, 056315.

Matteo, C., Candido, P., Vera, R. R., Francesca, V. (2012). Current and future nanotech applications in the oil industry. Am J Appl Sci, 9: 784793.

Mcelfresh, P., Holcomb, D., Ector, D. (2012). Application of Nanofluid Technology to Improve Recovery in Oil and Gas Wells. In Society of Petroleum Engineers, SPE-154827-MS.

Miranda, C. R., De Lara, L. S., Tonetto, B. C. (2012). Stability and mobility of functionalized silica nanoparticles for enhanced oil recovery application. Soc. Pet. Eng. SPE 157033-MS.

Mishra, P.C., Mukherjee, S., Kumar Nayak, S., Panda, A. (2014). A brief review on viscosity of nano fluids. J Int Nano Lett, 4: 109-120.

Mo, D., Yu, J., Liu, N., Lee, R. (2012). Study of the Effect of Different Factors on Nanoparticle-Stablized CO2 Foam for Mobility Control. In SPE Annual Technical Conference and Exhibition.

Mo, D., Yu, J., Liu, N., Lee, R. (2013). In 2013 SPE International Symposium on Oilfield Chemistry, SPE-129925-MS.

Mohajeri, M., Hemmati, M., Sadat Shekarabi, A. (2015). An experimental study on using a nanosurfactant in an EOR process ofheavy oil in a fractured micromodel. J Pet Sci Eng, 126: 162-173.

Mohammadi, M., Moghadasi, J., Naseri, S. (2014). An experimental investigation of wettability alteration in carbonate reservoir using $\gamma$ $\mathrm{Al}_{2} \mathrm{O}_{3}$ nanoparticles. Irani J Oil Gas Sci Tech, 3: 18-26.

Morrow, N. (1990). Wettability and its effect on oil recovery. J Pet Technol, 42: 1476-1485.

Morrow, N. R., Lim, H. T., Ward J. S. (1984). Effect of crude-oil-induced wettability changes on oil recovery. $59^{\text {th }}$ Annual Society of Petroleum Engineers of AIME Technical Conference, Houston, Texas (paper SPE 13215).

Morrow, N. R., Lim, H. T., Ward, J. S. (1986). Effect of crude-oilinduced wettability changes on oil recovery. SPE Form Eval, 89-103.

Munshi, A. M., Singh, V. N., Kumar, M., Singha, J. P. (2008). Effect of nanoparticle size on sessile droplet contact angle. J Appl Phys, 103: 084315.

Nguyen, P. T., Do, B. P., Pham, D. K., Nguyen, Q. T., Dao, D. Q., Nguyen, H. A. (2012). Evaluation on the EOR potential capacity of the synthesized composite silica-core/polymer-shell nanoparticles blended with surfactant systems for the HPHT offshore reservoir conditions. In SPE International Oilfield Nanotechnology Conference, SPE-157127-MS.

Ogolo, N. A., Olafuyi, O. A., Onyekonwu, M. O. (2012). Enhanced oil recovery using nanoparticles. Soc Pet. Eng. SPE. 160847-MS.

Onyekonwu, M. O., Ogolo, N. A. (2010). Investigating the use of nanoparticles in enhancing oil recovery. Paper No. 140744- MS, Nigeria, July 31 - August 7.

Orr, F. M., Taber, J. J. (1984). Use of carbon dioxide in enhanced oil recovery. Science, 224: 563-569.

Parvazdavani, M., Masihi, M., Ghazanfari, M. H., Sherafati, M., Mashayekhi, L. (2012). Investigation of the Effect of Water Based Nano-Particles Addition on Hysteresis of Oil and-Water Relative Permeability Curves. SPE 157005.The SPE International Oilfield Nanotechnology Conference held in Noordwijk, The Netherlands, 12.14 June.

Phenrat, T., Kim, H. J. ,Fagerlund, F., Illangasekare, T., Tilton, R. D., Lowry, G. V. (2009). Particle size distribution, concentration, and magnetic attraction affect transport of polymer-modified $\mathrm{Fe}(0)$ nanoparticles in sand columns. Environ Sci Technol, 43: 5079-5085.

Phenrat, T., Saleh, N., Sirk, K., Kim, H. J., Tilton, R. D., Lowry, G. V. (2008). Stabilization of aqueuous nanoscale zerovalent iron dispersions by anionic polyelectrolytes: adsorbed anionic polyelectrolyte layer properties and their effect on aggregation and sedimentation. J Nanopart Res, 10: 795-814.

Pickering, S. U. (1907). Emulsions. J Chem Soc Trans, 91: 2001-2021.

Piculell, L., Lindman, B. (1992). Association and segregation in aqueous polymer/polymer, polymer/surfactant. Adv Colloid Interf Sci, 4: $149-178$

Pope, G. (1980). The application of fractional flow theory to enhanced oil recovery. Soc Pet Eng J, 20: 191.

Pourafshary, P., Azimipour,S. S., Motamedi, P., Samet, M. (2009). Assessment of investment in development of nanotechnology in upstream petroleum industry. In: Proceedings of the Saudia Arabia Section Technical Symposium Exhibition. AlKhobar, Saudia Arabia, SPE No. 126101-MS

Qian, F., Cui, F., Ding, J., Tang, C., Yin, C. (2006). Chitosan graft copolymer nanoparticles for oral protein drug delivery: Preparation and characterization. Biomacromolecules, 7: 2722-2727.

Qiu, F. (2010). The Potential applications in heavy oil EOR with the nanoparticle and surfactant stabilized solvent-based emulsion.CSUG/SPE 134613.

Quaroni, L., Chumanov, G. (1999). Preparation of polymer-coated functionalized silver nanoparticles. J. Am. Chem. Soc., 121, 1064210643.

Quinn, J., Geiger, C., Clausen, C., Brooks, K., Coon, C., O'Hara, S., Krug, T., Major, D., Yoon, W.S., Gavaskar, A., Holdsworth, T. (2005). Field demonstration of DNAPL dehalogenation using emulsified zerovalent iron. Environ Sci Technol, 39: 1309-1318.

Ramsden, W. (1903). Seperation of solids in the surface-layers of solutions and 'suspension' (observations on surface-members, bubbles, and mechanical coagulation) - Preliminary account. Proc $\mathrm{R}$ Soc Lond, 72: 156-164.

Rao, D., Girard, M., Sayegh, S. (1992). The inûuence of reservoir wettability on waterûood and miscible flood performance. J Canad Petrol Tech, 31: 47-55.

Raterman, K. T., Kremesec Jr., V. J., Suffridge, F. E. (1988). Evaluat ion of low-concent ration surfactantflooding in the absence of mobility control agents. SPE/ DOE Paper No. 17394. SPE/DOE Enhanced Oil Recovery Symposium, Tulsa, Oklahoma, April 17-30.

Ravera, F., Santini, E., Loglio, G., Ferrari, M., Liggieri, L. (2006). Effect of nanoparticles on the interfacial properties of liquid/liquid andliquid/air surface layers. J Phys Chem, 110(39): 19543-19551.

Rosen, M. J., Wang, H., Shen, P., Zhu, Y. (2005). Ultralow interfacial tension for enhanced oil recovery at very low surfactant concentrations. Langmuir, 21: 3749- 3756.

Rossen, W. R., Gauglitz, P. A. (1990). Percolation theory of creation and mobilization of foams in porous media AIChE J, 36, 1176-1188).

Roussennac, B., Toschi, C. (2010). Brightwater Trial in Salema Field (ComposBasin, Brazil). In Society of Petroleum Engineers, SPE131299-MS. 
Roustaei, A., Bagherzadeh, H. (2015). Experimentalinvestigation of $\mathrm{SiO}_{2}$ nanoparticles on enhanced oil recovery of carbonate reservoirs. J Petrol Explor Prod Tech, 5: 27-33.

Roustaei, A., Saffarzadeh, S., Mohammadi, M. (2013). An evaluation of modified silica nanoparticles' efficiency in enhancing oil recovery of light and intermediate oil reservoirs. Egypt J Petrol, 22: 427-433.

Rungta, A., Natarajan, B., Neely, T., Dukes, D., Schadler, L. S., Benicewicz, B. C. (2012). Grafting bimodal polymer brushes on nanoparticles using controlled radical polymerization. Macromolecules, 45, 9303-9311.

Safari, M. (2014). Variations in wettability caused by nanoparticles. Petrol Sci Tech, 32: 1505-1511.

Saigal, T., Dong, H., Matyjaszewski, K., Tilton, R. D. (2010). Pickering emulsions stabilized by nanoparticles with thermally responsive grafted polymer brushes. Langmuir, 26: 15200-15209.

Saigal, T., Yoshikawa, A., Kloss, D., Kato, M., Golas, P. L., Matyjaszewski, K., Tilton, R. D. (2013). Stable emulsions with thermally responsive microstructure and rheology using poly(ethylene oxide) star polymers as emulsifiers. J Colloid Interface Sci, 394: 284292.

Saleh, N., Phenrat, T., Sirk, K., Dufour, B., Ok, J., Sarbu,T., Matyjaszewski, K., Tilton, R. D., Lowry, G. V. (2005). Adsorbed triblock copolymers deliver reactive iron nanoparticles to the oil/water interface. Nano Lett., 5: 2489-2494.

Saleh, N., Sarbu, T., Sirk, K., Lowry, G. V., Matyjaszewski, K., Tilton, R. D. (2005). Oil-in-water emulsions stabilized by highly charged polyelectrolyte-grafted silica nanoparticles. Langmuir, 21: 9873-9878.

Saleh, N., Sirk, K., Liu, Y., Phenrat, T., Dufour, B., Matyjaszewski, K., Tilton, R. D., Lowry, G. V. (2007). Surface modifications enhance nanoiron transport and NAPL targeting in saturated porous media. Environ Eng Sci, 24: 45-57.

Salehi, M., Johnson, S. J., Liang, J. T. (2008). Mechanistic study of wettability alteration using surfactants with applications in naturally fractured reservoirs. Langmuir, 24: 14099-14107.

Sanele, S., Yortsos, Y. C. (1986). A note on the application of the theory of coherence to surfactant flooding. SPE Reserv Eng, 1: 2328.

Sani, A. M., Mohanty, K. K. (2009). Incorporation of clay nano-particles in aqueous foams. Colloids Surf. A Physicochem Eng Aspects, 340: 174-181.

Sanz, C. A., Pope, G. A. (1995). Alcohol-free chemicalflooding: From surfactant screening to coreflood design. SPEPaper No. 28956. SPE International Symposium on Oilfield Chemistry, San Antonio, Texas, February 14-17.

Saunders, B. R., Turner, M. L. (2008). Nanoparticle-polymer photovoltaic cells. Adv Colloid Interface Sci, 138: 1-23.

Schmidt, R. L., Chevron, O. F. R. C. (1988). Chem Eng Prog, 86.

Schrick, B., Hydutsky, B. W., Blough, J. L., Mallouk, T. E. (2004). Delivery vehicles for zerovalent metal nanoparticles in soil and groundwater. Chem Mater, 16: 2187-2193.

Shah, D. O. (1977). Improved Oil Recovery by Surfactant and Polymer Flooding. Elsevier: New York.

ShamsiJazeyi, H., Verduzco, R., Hirasaki, G. J. (2014). Reducing adsorption of anionic surfactant for enhanced oil recovery: Part I. Competitive adsorption mechanism. Coll Surf A: Physicochem Eng Aspects, 453: 162-167.

Sheng, J. (2011). Modern chemical enhanced oil recovery. Gulf Profession Publishing. 101-206.

Shiran, B. S., Skauge, A. (2013). Enhanced oil recovery (EOR) by combined low salinity water/polymer flooding. Energy Fuels, 27: 1223-1235.

Singh, S., Ahmed, R. (2010). Vital role of nanopolymers in drilling and simulations fluid applications. Paper SPE 130413 presented at the SPE annual technical conference and exhibition, Florence, Italy.

Siripurapu, S., DeSimone, J. M., Khan, S. A., Spontak, R. J. (2005). Controlled foaming of polymer films through restricted surface diffusion and the addition of nanosilica particles or $\mathrm{CO}_{2}$-philic surfactants. Macromolecules, 38: 2271-2280.

Skauge, T., Hetland, S., Spildo, K., Skauge A. (2010). Nano-sized particles for EOR, SPE 129933,SPE Improved Oil Recovery Symposium, Oklahoma, USA, 24-28 April.

Soppimath, K. S., Aminabhavi, T. M., Kulkarni, A. R., Rudzinski, W. E.
(2001). Biodegradable polymeric nanoparticles as drug delivery devices. J Control Release, 70: 1-20.

Stahl, C. R., Gibson, M. A., Knudsen, C. W. (1987). U.S. Pat. 4, $694,907$.

Stahl, G. A., Schulz, D. N. (1988). Water-Soluble Polymers for Petroleum Recovery. Springer: New York.

Standnes, D. C., Austad, T. (2003). Wettability alteration in carbonates: Interaction between cationic surfactant and carboxylates as a key factor in wettability alteration from oil-wet to water-wet conditions. Colloids Surf A, 216: 243-259.

Suleimanov, B. A., Ismailov, F. S., Veliyev, E. F. (2011). Nanofluid for enhanced oil recovery. J Pet Sci Eng, 78: 431-437.

Sun, F. C., Dobrynin, A. V., Shirvanyants, D., Lee, H. I., Matyjaszewski, K., Rubinstein, G. J., Rubinstein, M., Sheiko, S. S. (2007). Flory theorem for structurally asymmetric mixtures. Phys Rev Lett, 99: 137801

Taber, J. J. (1981). In Surface Phenomena in Enhanced Oil Recovery. Shah, D. O. Ed.; Springer: US. p 13.

Takafuji, M., Ide, S., Ihara, H., Xu, Z. (2004). Preparation of poly(1vinylimidazole)-grafted magnetic nanoparticles and their application for removal of metal ions. Chem Mater, 16: 1977-1983.

Talash, A. W., Strange, L. K. (1982). Summary of Performance and Evaluations in the West Burkburnett Chemical Waterflood Project "JP 7 ". pp: 2495-2502.

Tata, B. V. R., Boda, D., Henderson, D., Nikolov, A., Wasan, D. T. (2000). Structure of charged colloids under a wedge confinement. Phys Rev E, 62: 3875-3881.

Taugbel, K., Ly, T. V., Austad, T. (1995). Chemical flooding of oil reservoirs 3. Dissociative surfactant-polymer interaction with a positive effect on oil recovery. Colloids Surf A: Physicochem. Eng Aspects, 10: 83-90.

Taylor, K. C., Nasr-El-Din, H. A. (1998). Water-soluble hydrophobically associating polymers for improved oil recovery: A literature review. J Pet Sci Eng, 19: 265-280.

Tian, Y., Wang, L., Tang, Y., Liu, C., Ma, C., Wang, T. (2012). Research and application of nanopolymer microspheres diversion technique of deep fluid. Soc. Pet. Eng. SPE. 156999-MS.

Torchilin, V. P., Trubetskoy, V. S. (1995). Which polymers can make nanoparticulate drug carriers long-circulating? Adv. Drug Delivery Rev, 16: 141-155.

Torsaeter, O., Li, S., Hendraningrat, L. (2013). Effect of Some Parameters Influencing Enhanced Oil Recovery Process using Silica Nanoparticles. SPE Reservoir Characterization and Simulation Conference and Exhibition. Abu Dhabi, UAE, 16-18 September.

Torsaeter, O., Hendraningrat L. (2013). Effect of some Parameters influenced Oil Recovery Process using Silica Nanoparticles, SPE Reservoir Characterization and Simulation Conference and Exhibition. Abu Dhabi, UAE, 16-18 September.

Towns, M., Denyer, P., Nabil, M., Kinawy, M., Thrasher, D., Bayoumi, R., Lara Angarita, M. (2013). Enhancing Oil Recovery in Gulf of Suez by Deep Conformance Control using a Thermally Activated Particle System. North AfricaTechnical Conference \& Exhibition.

Trokhymchuk, A., Henderson, D., Nikolov, A., Wasan, D.T. (2001). A simple calculation of structural and depletion forces for fluids/suspensions confined in a film. Langmuir, 17: 4940-4947.

Udayana, R. J. K., Kalescky, R. J. B., Chiu, C., Nielsen, S. O. (2010). Molecular dynamics simulations of surfactant functionalized nanoparticles in the vicinity of an oil/water interface. J Phys Chem C, 114: $12151-12157$

Van Oss C. J., Giese R. F. (1995). The hydrophilicity and hydrophobilicity of clay minerals. Clays Clay Miner, 43:474-477.

Wang, D. M., Xia, H. F., Liu, Z. C., Yang, Q. Y. (2001). Study of the mechanism of polymer solution withviscoelastic behavior increasing microscopic oil displacement efficiency and the mechanism of polymer solution with viscoelastic behavior increasing microscopic oil displacememt effeciency and the Forming of Steady " Oil Thread " Flow Channels, SPE Aisa Pacific Oil and Gas Conference and Exhibition,17-19 April, Jakarta.

Wang, D., Cheng, J., Wu, J., Wang, Y. (2002). Producing by polymer flooding more than 300 million barrels of oil what experienceshave been learnt. SPE 77872 presented at Aisa Pacific oil and gas conference and exhibition, Melborne, Australia. 
Wang, D., Zhao, L., Cheng, J., Wu, J. (2003). Actual field data show that production costs of polymer flooding can be lower than water flooding. SPE 84849 presented at improved oil recovery conference in Asia Pacific, Kuala Lumpur, Malaysia, 20-21 October 2003. Publishing 101-206.

Wang, J., Dong, M., (2009). Optimum effective viscosity of polymer solution for improving heavy oil recovery. J Petrol Sci Eng, 67: 155158.

Wang, K. L., Cheng Liang, S., Wang, C. C. (2010). Research of improving water injection effect by using active $\mathrm{SiO}_{2}$ nanopowderin the low-permability oil field. Adv Mater Res, 92:207-212.

Wang, P., Zakeeruddin, S. M., Comte, P., Charvet, R., Humphry-Baker, R., Grätzel, M. (2003). Enhance the performance of dye-sensitized solar cells by co-grafting amphiphilic sensitizer and hexadecylmalonic acid on $\mathrm{TiO}_{2}$ nanocrystals. J Phys Chem B, 107: 14336-14341.

Wasan, D. T., Nikolov, A. (2003). Spreading of nanofluids on solids. Nature, 423: 156-159.

Wasan, D. T., Nikolov, A., Kondiparty, K. (2011). The wetting and spreading of nanofluids on solids: Role of the structural disjoining pressure. Curr Opin Colloid Interf Sci, 16: 344-349.

Worthen, A. J., Bryant, S. L., Huh, C., Johnston, K. P. (2013). Carbondioxide in-water foams stabilized with nanoparticles and surfactant acting in synergy. AIChE J, 59: 3490-3501.

Wu, S., Firoozabadi, A. (2010). Permanent alteration of porous media wettability from liquid-wetting to intermediate gas-wetting. Transp Porous Media, 85: 189-213.

Wu, Z., Yu, J., Cheng, T., Yue, X., Yang, H. (2014) Effect of viscosity and interfacial tension of surfactant - polymer flooding on oil recovery in high-temperature and high-salinity reservoirs. J Petrol Explor Prod Technol, 4: 9-16.

Xiangling, K., Ohadi, M. (2010). Abu Dhabi international petroleum exhibition and conference. SPE-138241-MS.

Xue, L., Agarwal, U. S., Lemstra, P. J. (2005). Shear degradation resistance of star polymers during elongational flow. Macromolecules, 38: 8825-8832.

Yadali, J. B., Kharrat, R., Ahmadloo, F. (2009). Selection of proper criteria in flow behavior characterization of low tension polymer flooding in heavy oil reservoirs. SPE Kuwait international petroleum conference and exhibition. Kuwait City, Kuwait.

Yan, C., Kan, A., Wang, W., Wang, L., Tomson, M. (2012). In Society of Petroleum Engineers, SPE-155627-MS.

Yang, G., Tu, H., Hung, C. (2007). Stability of nanoiron slurries and their transport in the subsurface environment. Sep. Purif Technol, $58,166-172$

Yang, H. D., Wadleigh, E. E. (2000). Dilute surfactant IOR. Design improvement for massive, fractured carbonate applications. SPE Paper No. 59009. 2000 SPE International Petroleum Conference and Exhibition, Villa Hermosa, Mexico, February 1-3.

Ye, Z. B., Gou, G. J., Gou, S.H., Jiang, W. C., Liu, T. Y. (2013). Synthesis and characterization of water-soluble sulfonates copolymer of acrylamide and $\mathrm{N}$-allylbenzamide as enhanced oil recovery chemical. J Appl Polym Sci, 128: 2003-2011.

Ye, Z., Qin, X., Lai, N., Peng, Q., Li, X., Li, C. (2013). Synthesis and performance of an acrylamide copolymer containing nano- $\mathrm{SiO}_{2}$ as enhanced oil recovery chemical. Hind Pub Crop J Chem, Volume 2013, Article ID 437309, 10 pages.

Yefei, W., Huaimin, X. Weizhao, Y., Baojun, B., Xinwang, S., Jichao, Z. (2011). Surfactant induced reservoir wettabilityalteration: Recent theoretical and experimental advances in enhanced oil recovery. Pet Sci, 8: 463-476.

Yong, Y., Bai, Y., Li, Y., Lin, L., Cui, Y., Xia, C. (2008). Preparation and application of polymer-grafted magnetic nanoparticles for lipase immobilization. J Magn Magn Mater, 320: 2350-2355.

Yu, H., Kotsmar, C., Yoon, K. Y., Ingram, D. R., Johnston, K. P., Bryant, S. L., Huh, C. (2010). Transport and retention of aqueous dispersions of paramagnetic nanoparticles in reservoir rocks. In: SPE improved oil recovery symposium, Tusla, OK, USA.

Yu, J., An, C., Mo, D., Liu, N., Lee, R. (2012). Study of adsorption and transportation behavior of nanoparticles in three different porous media. In SPE Improved Oil Recovery Symposium, SPE-153336-MS.

Yu, J., Liu, N., Li, L., Lee, R. (2012). In CMTC Conference, CMTC150849-MS
Yuan, W., Liu, X., Wei, H., Liu, J., Yang, H., Hu, S., Li, Y., Wang, D. (2010). Research and application effect of polymeric microsphere in Wen-10 of Sinopec Zhongyuan Oil field. Inner Mong Petrochem, 12: 122-126.

Zargartalebi, M., Kharrat, R., Barati, N. (2015). Enhancement of surfactant flooding performance by the use of silica nanoparticles. Fuel, 143: 21-27.

Zhan, J., Zheng, T., Piringer, G., Day, C., Mcpherson, G. L., Lu, Y., Papadopoulos, K., John, V. T. (2008). Transport characteristics of nanoscale functional zerovalent iron/silica composites for in situ remediation of trichloroethylene. Environ Sci Technol, 42: 8871-8876.

Zhang, H., Dong, M., Zhao, S. (2012). Experimental study of the interaction between $\mathrm{NaOH}$, surfactant, and polymer in reducing court heavy oil/brine interfacial tension. Energy Fuels, 26: 3644-3650.

Zhang, J., Misra, R. D. K. (2007). Magnetic drug-targeting carrier encapsulated with thermosensitive smart polymer: Core-shell nanoparticle carrier and drug release response. Acta Biomater, 3: 838-850.

Zhang, T., Davidson, A., Brytant, S. L., Huh, C. (2010). Nanoparticlestabilized Emulsions for Application in Enhanced Oil Recovery, SPE Improved Oil Recovery Symposium, Tulsa, Oklahoma, USA, 24-28 April 2010

Zhang, T., Espinosa, D., Yoon, K. Y., Rahmani, A. R., Yu, H., Caldelas, F., Ryoo, S., Roberts, M., Prodanovic, M., Johnston, K., Milner T. E., Bryant S. L., Huh C. (2011). Engineered Nanoparticles as HarshCondition Emulsion and Foam Stabilizers and as Novel Sensors. In The Offshore Technology Conference, OTC-21212-MS.

Zhang, X., Yang, H., Xiong, H. M., Li, F.Y., Xia, Y. Y. (2006) J Power Sources, 160: 1451-1455.

Zhong, C., Hmeuang, R., Zhang, X., Dai, H., (2007). Synthesis, characterization, and solution properties or an acrylamide based terpolymer with butyl styrene. J Appl Polym Sci, 103: 4027-4038.

Zhou, X., Morrow, N. R., Ma, S. (2000). Interrelationship of wettability, initial water saturation, aging time, and oil recovery by spontaneous imbibition and waterflooding. SPE J, 5: 199-207.

Citation: El Shafey A. M. (2017). Effect of nanoparticles and polymer nanoparticles implementation on chemical flooding, wettability and interfacial tension for the enhanced oil recovery (EOR) processes. Afr J Eng Res, 5(3): 35-53. 